medRxiv preprint doi: https://doi.org/10.1101/2020.05.22.20109777; this version posted August 19, 2020. The copyright holder for this preprint (which was not certified by peer review) is the author/funder, who has granted medRxiv a license to display the preprint in It is made available under a CC-BY-NC-ND 4.0 International license.

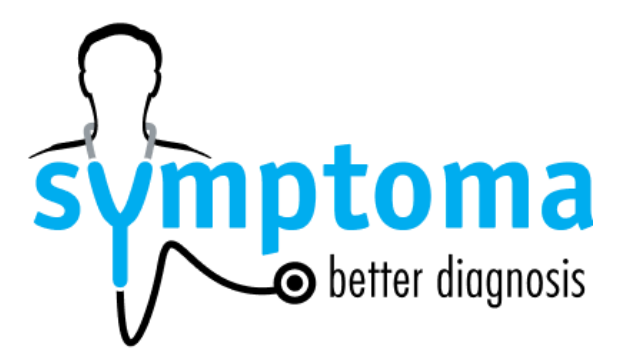

\title{
A benchmark of online COVID-19 symptom checkers
}

Nicolas Munsch', Alistair Martin', Stefanie Gruarin², Jama Nateqi ${ }^{2,3}$, Isselmou Abdarahmane1, Rafael Weingartner-Ortner ${ }^{1,2}$, Bernhard Knapp ${ }^{1 *}$

${ }^{1}$ Symptoma, Data Science Department, Vienna, Austria

2 Symptoma, Medical Department, Attersee, Austria

${ }^{3}$ Department of Internal Medicine, Paracelsus Medical University, Salzburg, Austria 
medRxiv preprint doi: https://doi.org/10.1101/2020.05.22.20109777; this version posted August 19, 2020. The copyright holder for this preprint (which was not certified by peer review) is the author/funder, who has granted medRxiv a license to display the preprint in It is made available under a CC-BY-NC-ND 4.0 International license.

\section{Symptoma \\ A benchmark of online COVID-19 symptom checkers}

\section{Abstract}

\section{Background}

A large number of online COVID-19 symptom checkers and chatbots have been

developed but anecdotal evidence suggests that their conclusions are highly variable.

To our knowledge, no study has evaluated the accuracy of COVID-19 symptom checkers in a statistically rigorous manner.

\section{Methods}

In this paper, we evaluate 10 different COVID-19 symptom checkers screening 50

COVID-19 case reports alongside 410 non-COVID-19 control cases.

\section{Results}

We find that the number of correctly assessed cases varies considerably between different symptom checkers, with Symptoma $\left(F_{1}=0.92, M C C=0.85\right)$ showing the overall best performance followed by Infermedica $\left(F_{1}=0.80, M C C=0.61\right)$.

\section{Introduction}

In the modern world, large numbers of patients initially turn to various online sources for self-diagnoses before seeking diagnoses from a trained medical professional. But web sources have inherent problems such as misinformation, misunderstandings, misleading advertisements and varying quality [1]. Interactive examples of web sources developed to meet the need of online diagnoses are sometimes referred to as symptom 
medRxiv preprint doi: https://doi.org/10.1101/2020.05.22.20109777; this version posted August 19, 2020. The copyright holder for this preprint (which was not certified by peer review) is the author/funder, who has granted medRxiv a license to display the preprint in It is made available under a CC-BY-NC-ND 4.0 International license.

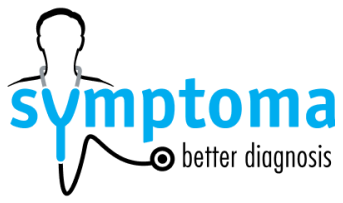

\section{A benchmark of online COVID-19 symptom checkers}

checkers or chatbots [2][3]. Based on a list of entered symptoms and other factors, symptom checkers return a list of potential diseases.

Online symptom checkers have become popular in the context of the novel coronavirus disease 2019 (COVID-19) pandemic as access to doctors is reduced, worry in the population is high, and lots of misinformation is circulating the web [1]. On COVID-19 symptom checker web pages users are asked a series of COVID-19 specific questions and, upon completion, an association between the answers and COVID-19 is given alongside behavioural recommendations, e.g., self-isolate.

COVID-19 symptom checkers are valuable tools for pre-assessment and screening during this pandemic, both taking pressure off from clinicians and reducing footfall within hospitals. A large number of symptom checkers specific to COVID-19 have been developed. Anecdotal evidence (e.g. a newspaper article [4]) suggests that their conclusions differ with possible implications on the quality of the symptom assessment. To our knowledge, there exist no studies comparing and evaluating COVID-19 symptom checkers.

In the following, we present a study evaluating 10 different COVID-19 online symptom checkers using 50 COVID-19 cases extracted from the literature and 410 non-COVID-19 control cases of patients with other diseases. We find that the COVID-19 symptom checkers' classification of many patient cases differ as well as their accuracies. Symptoma $(F 1=0.92, M C C=0.85)$ shows the overall best performance followed by Infermedica $(\mathrm{F} 1=0.80, \mathrm{MCC}=0.61)$. 
medRxiv preprint doi: https://doi.org/10.1101/2020.05.22.20109777; this version posted August 19, 2020. The copyright holder for this preprint (which was not certified by peer review) is the author/funder, who has granted medRxiv a license to display the preprint in It is made available under a CC-BY-NC-ND 4.0 International license.

\section{Sobetter diagnosis}

A benchmark of online COVID-19 symptom checkers

\section{Methods}

\section{COVID-19 symptom checkers}

Ten COVID-19 symptom checkers that were freely available online between 3rd and 9th of April 2020 were selected for this study (Table 1). These symptom checkers were used in the versions available in this date range and updates after this date were not considered for analysis.

As a baseline for the performance evaluation of the 10 online COVID-19 symptom checkers, we developed two additional simplistic symptom checkers. These two checkers evaluate and weigh the presence of WHO [5] provided COVID-19 symptom

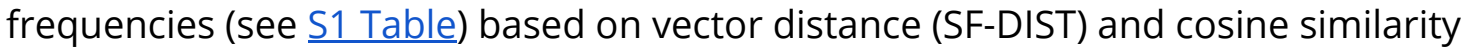
(SF-COS). These approaches can be implemented in a few lines of code (see $\underline{\text { S2 Text). }}$. 
medRxiv preprint doi: https://doi.org/10.1101/2020.05.22.20109777; this version posted August 19, 2020. The copyright holder for this preprint (which was not certified by peer review) is the author/funder, who has granted medRxiv a license to display the preprint in It is made available under a CC-BY-NC-ND 4.0 International license.

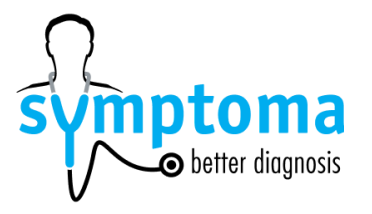

A benchmark of online COVID-19 symptom checkers

Table 1:

List of online COVID-19 symptom checkers included in this study.

$\begin{array}{ll}\text { Name } & \text { URL } \\ \text { Ada } & \text { https://ada.com/covid-19-screener/ } \\ \text { Apple } & \text { https://www.apple.com/covid19 } \\ \text { Babylon } & \text { https://www.babylonhealth.com/ask-babylon-chat } \\ \text { CDC } & \text { https://www.cdc.gov/coronavirus/2019-ncov/symptoms-testing/symptoms.html } \\ \text { Cleveland Clinic } & \text { http://covid19chat.clevelandclinic.org/ } \\ \text { Docyet } & \text { https://corona.docyet.com/client/index.html } \\ \text { Infermedica } & \text { https://symptomate.com/covid19/checkup/en/ } \\ \text { Providence } & \text { https://coronavirus.providence.org/ } \\ \text { Symptoma } & \text { https://www.symptoma.com/covid-19 } \\ \text { Your.MD } & \text { https://webapp.your.md/login }\end{array}$

\section{Clinical cases}

We used a total of 460 clinical cases to evaluate the performance of the COVID-19 symptom checkers. Each case lists both symptoms and the correct diagnosis, alongside the age and sex of the patient when available. Details of the two case sets used are given below and in Table 2.

\section{COVID-19 cases}

A total of 50 COVID-19 cases were extracted by three trained medical doctors from the

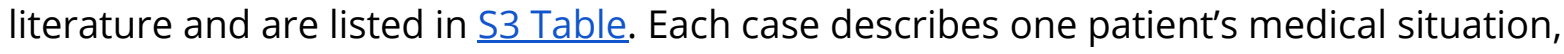


medRxiv preprint doi: https://doi.org/10.1101/2020.05.22.20109777; this version posted August 19, 2020. The copyright holder for this preprint (which was not certified by peer review) is the author/funder, who has granted medRxiv a license to display the preprint in It is made available under a CC-BY-NC-ND 4.0 International license

Oobtter diagnosis

\section{A benchmark of online COVID-19 symptom checkers}

i.e. symptoms experienced or COVID-19 contacts. Extreme edge cases of COVID-19 such as patients with several severe comorbidities were not included in this study.

\section{Control cases}

COVID-19 cases allow us to evaluate the sensitivity of symptom checkers. To also evaluate the specificity, 410 control cases from the British Medical Journal (BMJ) were sourced [6,7]. To allow a fair assessment, we only used cases containing at least one of

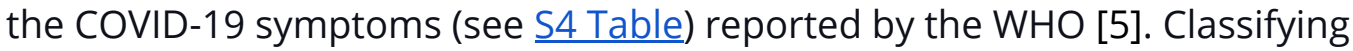
non-relevant cases (e.g., a fracture) would overestimate the symptom checkers' specificity. Furthermore, these patients would not consult an online COVID-19 symptom checker. None of these 410 BMJ cases has COVID-19 listed as the diagnosis as the cases where collected before the COVID-19 outbreak.

\section{Table 2:}

Number of symptoms in case sets

\begin{tabular}{|c|c|c|c|c|}
\hline case set & Number of cases & Number of symptoms & Age & Sex \\
\hline $\begin{array}{l}\text { COVID-19 } \\
\text { cases }\end{array}$ & 50 & $\begin{array}{l}8.2 \pm 4.1 \\
(\text { median } 7)\end{array}$ & $\begin{array}{l}45.6 \pm 16.9 \\
\text { (median } 45)\end{array}$ & $\begin{array}{l}50 \% \text { male } \\
428 \text { female } \\
8 \% \text { unknown }\end{array}$ \\
\hline $\begin{array}{l}\text { BMJ control } \\
\text { cases }\end{array}$ & 410 & $\begin{array}{l}9.8 \pm 4.4 \\
\text { (median } 9 \text { ) }\end{array}$ & $\begin{array}{l}38.6 \pm 22.4 \\
\text { (median } 38 \text { ) }\end{array}$ & $\begin{array}{l}588 \text { male } \\
398 \text { female } \\
38 \text { unknown }\end{array}$ \\
\hline
\end{tabular}


medRxiv preprint doi: https://doi.org/10.1101/2020.05.22.20109777; this version posted August 19, 2020. The copyright holder for this preprint (which was not certified by peer review) is the author/funder, who has granted medRxiv a license to display the preprint in It is made available under a CC-BY-NC-ND 4.0 International license

\section{Accuracy evaluation}

For statistical analysis we used the following classification:

- True-positive (TP): COVID-19 case classified as COVID-19

- False-positive (FP): non-COVID-19 case classified as COVID-19

- True-negative (TN): non-COVID-19 case classified as non-COVID-19

- False-negative (FN): COVID-19 case classified as non-COVID-19

For each symptom checkers, we calculate the following metrics :

Sensitivity ( $=$ true positive rate $)=\frac{T P}{T P+F N}$

Specificity $(=$ true negative rate $)=\frac{T N}{F P+T N}$

F1 score (= harmonic mean of the precision and recall $)=\frac{2 . T P}{2 . T P+F P+F N}$

Matthews Correlation Coefficient $(\mathrm{MCC})=\frac{T P \cdot T N-F P \cdot F N}{\sqrt{(T P+F P) \cdot(T P+F N) \cdot(T N+F P) \cdot(T N+F N)}}$

\section{Classification of symptom checkers' outputs}

Most COVID-19 symptom checkers return a human-readable text which contains an association between entered symptoms and COVID-19. We classified these associations into three different categories: high risk, medium risk and low risk. Examples of a high, medium and low risk classifications are "There is a high risk that COVID-19 is causing your symptoms", "Your symptoms are worrisome and may be related to COVID-19" and “There's nothing at present to suggest that you have coronavirus (COVID-19). Please practice physical/social distancing" respectively. Our full text-output to risk mapping for all symptom checkers and all text outputs is given in $\mathrm{S5}$ Table. 
medRxiv preprint doi: https://doi.org/10.1101/2020.05.22.20109777; this version posted August 19, 2020. The copyright holder for this preprint (which was not certified by peer review) is the author/funder, who has granted medRxiv a license to display the preprint in It is made available under a CC-BY-NC-ND 4.0 International license

SViber diagnosis

\section{A benchmark of online COVID-19 symptom checkers}

Some symptom checkers only have two possible outputs: COVID-19 risk or no COVID-19 risk. In order to make symptom checkers with three and two risk levels comparable we performed two analysis versions: (a) medium risk and high risk is treated as COVID-19 positive (and low risk as COVID-19 as negative) and (b) high risk is treated as COVID-19 positive (and low risk and medium risk as COVID-19 negative).

\section{Bootstrapping}

To evaluate the robustness of our statistical measures and account for the unbalanced dataset, we performed bootstrapping across our cases. A total of 3000 random samples consisting of 50 COVID-19 cases and 50 control cases were created by sampling with replacement from the original set of 50 COVID-19 cases and the 410 control cases.

\section{Sensitivity and specificity}

In order to analyse the performance of the 10 online symptom checkers, we calculated the sensitivity and the specificity of each symptom checker based on the cases described in the method section. A scatterplot between sensitivity and specificity to COVID-19 of the different symptom checkers is given in Fig 1 and detailed numerics in

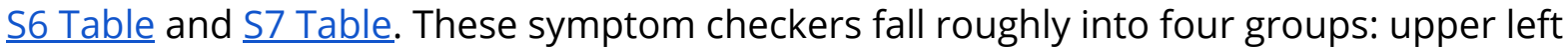
corner, lower right corner, central region, upper right corner.

Further analysis of true and false case classifications of these groups shows that the group in the upper left corner is composed of symptom checkers that require one (or 
medRxiv preprint doi: https://doi.org/10.1101/2020.05.22.20109777; this version posted August 19, 2020. The copyright holder for this preprint (which was not certified by peer review) is the author/funder, who has granted medRxiv a license to display the preprint in It is made available under a CC-BY-NC-ND 4.0 International license

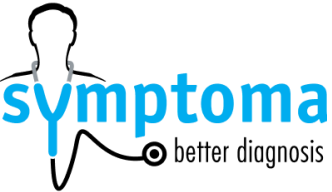

\section{A benchmark of online COVID-19 symptom checkers}

few) highly specific symptoms to be present in order to classify a case as COVID-19 positive (e.g. "intensive contact with a COVID-19 positive person"). By this way, these symptom checkers miss many COVID-19 positive patients that did not report exactly this highly specific symptom. Vice versa such highly specific symptoms are hardly present in non-COVID-19 cases. This results in low sensitivity and high specificity. The group in the lower right corner is composed of symptom checkers which predict a case as COVID-19 positive based on the presence of one or few COVID-19 associated symptoms, e.g. the presence of fever or cough is enough to predict a patient as COVID-19 positive. These checkers classify nearly every patient that has a respiratory disorder or viral infection as COVID-19 positive. As such, they do not miss many COVID-19 patients but wrongly predict many non-COVID-19 patients as COVID-19 positive. This results in low specificity and high sensitivity. The group in the more central region is composed of symptom checkers which use a more balanced prediction but exhibit limited success correctly classifying COVID-19 and non-COVID-19 patients.

The group in the upper right corner is composed of symptom checkers which also use a more balanced "symptoms to COVID-19 association model" but in this case, the classification between COVID-19 and non-COVID-19 patients is more successful. 
medRxiv preprint doi: https://doi.org/10.1101/2020.05.22.20109777; this version posted August 19, 2020. The copyright holder for this preprint (which was not certified by peer review) is the author/funder, who has granted medRxiv a license to display the preprint in It is made available under a CC-BY-NC-ND 4.0 International license.

\section{SU better diagnosis}

\section{A benchmark of online COVID-19 symptom checkers}

A COVID-19 positive defined by high risk

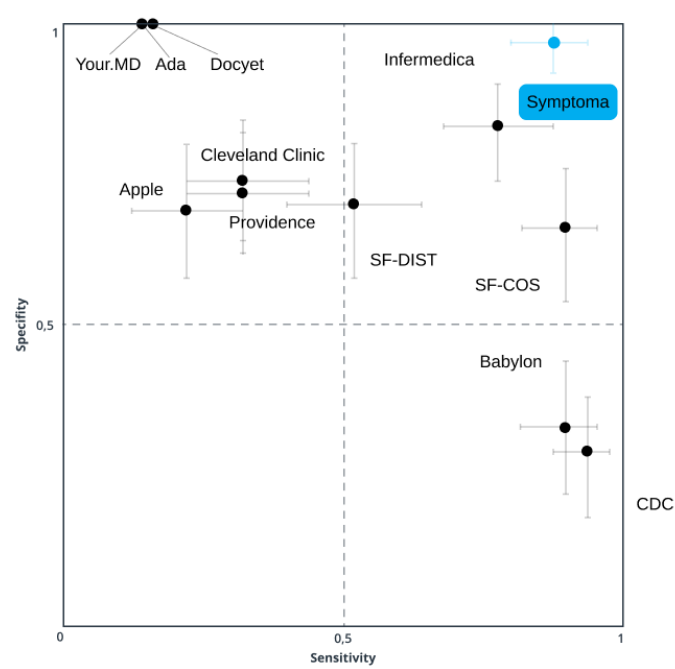

B COVID-19 positive defined by medium and high risk

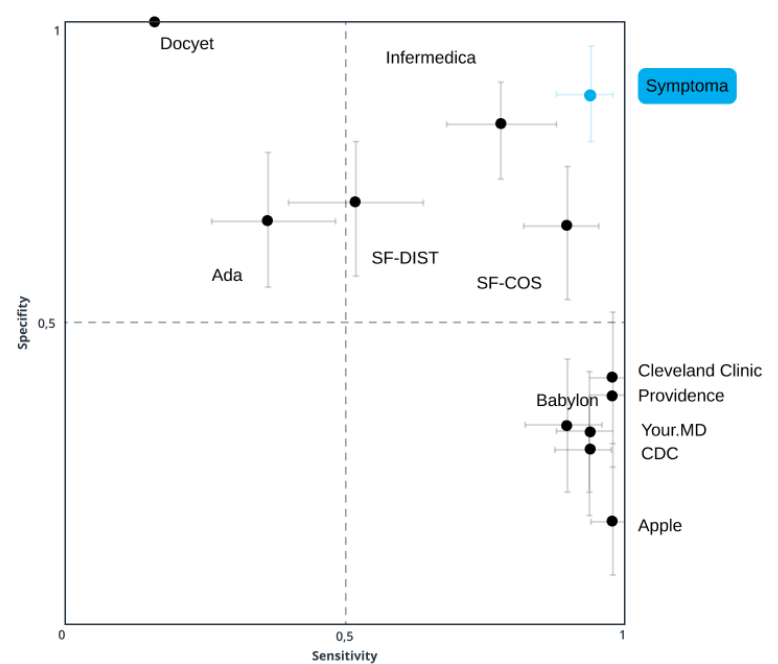

Fig 1. Sensitivity and specificity to COVID-19 cases. The mean of the 3000 random samples and 90\% bootstrap confidence interval are reported as dots and crosses respectively. (A) High risk: A COVID-19 positive prediction is defined only by a high risk returned by a symptom checker. (B) Medium-High risk: A COVID-19 positive prediction is defined by either a medium risk or high risk returned by a symptom checker.

\section{Constraining symptoms for Symptoma}

As Symptoma exhibits the best combination of sensitivity and specificity, we focused our analysis on Symptoma's performance. Symptoma allows free-text input of one's symptoms and thereby a more precise representation of the clinical test cases. The other symptom checkers do not allow free text input which limits the number of possible symptoms considerably (Fig 2A). In order to investigate how Symptoma would perform if constrained, we performed pairwise comparisons where Symptoma is only 
medRxiv preprint doi: https://doi.org/10.1101/2020.05.22.20109777; this version posted August 19, 2020. The copyright holder for this preprint (which was not certified by peer review) is the author/funder, who has granted medRxiv a license to display the preprint in It is made available under a CC-BY-NC-ND 4.0 International license

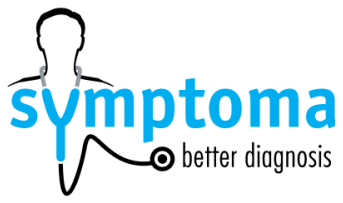

\section{A benchmark of online COVID-19 symptom checkers}

allowed to use the symptoms of another symptom checker. In this setup, Symptoma is massively disadvantaged as it can not use its full abilities. For example, in the pairwise comparison with "Your.MD", Symptoma considers only "fever", "dry cough", "shortness of breath", and "contact with a confirmed COVID-19 case" for the classification of cases. The results of this analysis are summarised in Fig 2B, the sensitivity and specificity

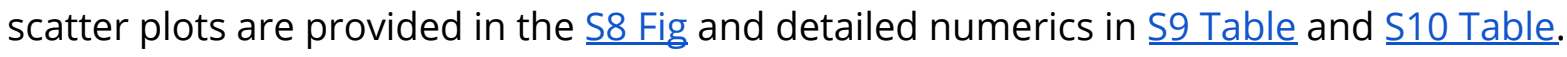
Under these constraints and when COVID-19 positive is defined by high risk only, Symptoma still significantly outperforms Apple and Cleveland Clinic, while performing statistically similar to six of the remaining symptom checkers (upper panel of Fig 2B). When COVID-19-positive is defined by high and medium risk (lower panel of Fig 2B), Symptoma's constrained performance is similar to seven of the other checkers, while outperforming Ada and Docyet. For Apple, Babylon, CDC, Cleveland Clinic, Providence and "Your.MD" the performance is about the same. When Symptoma is allowed to use all symptoms of the case descriptions, it clearly outperforms all other checkers (dashed blue line in Fig 2B). This suggests that performance is directly related to the number of symptom's any given checker considers as input, and as such, free-text input (non-constrained) will normally lead to a higher likelihood of correct diagnosis. 
medRxiv preprint doi: https://doi.org/10.1101/2020.05.22.20109777; this version posted August 19, 2020. The copyright holder for this preprint (which was not certified by peer review) is the author/funder, who has granted medRxiv a license to display the preprint in It is made available under a CC-BY-NC-ND 4.0 International license.

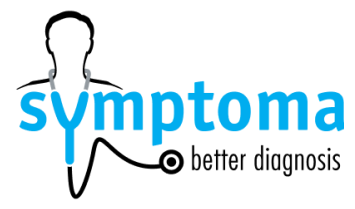

A benchmark of online COVID-19 symptom checkers

A

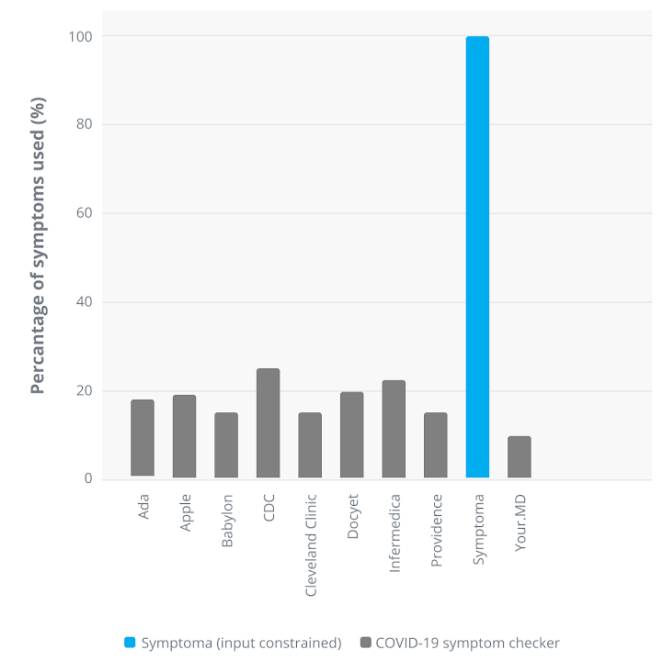

B COVID-19 positive defined by high risk

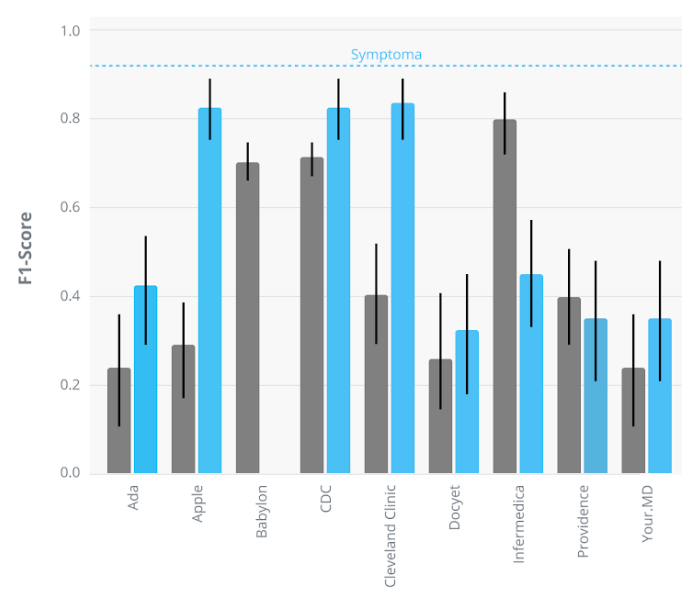

COVID-19 positive defined by medium and high

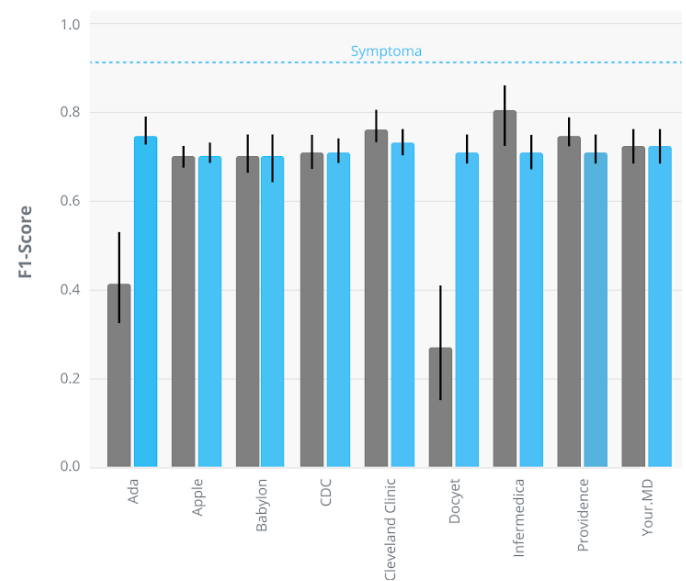

Fig 2. (A) Percentage of symptoms used for case classifications by each symptom checker relative to the total number of symptoms contained in all cases. (B) Symptoma input-constrained evaluation: Pairwise comparison between all symptom checkers and Symptoma based on the F1 score if only the subset of symptoms used by one checker is also used for Symptoma. The same analysis based on the MCC is shown in the $\underline{\mathbf{S 1 1} \text { Fig. }}$ Please note that using only Babylon's symptom inputs all cases are either classified medium or low risk by Symptoma and therefore there is no bar in the upper panel for Babylon's Symptoma. 
medRxiv preprint doi: https://doi.org/10.1101/2020.05.22.20109777; this version posted August 19, 2020. The copyright holder for this preprint (which was not certified by peer review) is the author/funder, who has granted medRxiv a license to display the preprint in It is made available under a CC-BY-NC-ND 4.0 International license.

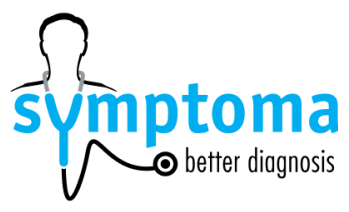

A benchmark of online COVID-19 symptom checkers

\section{Discussion}

We classified 50 COVID-19 case descriptions from the recent literature as well as 410 non-COVID-19 control cases with ten different online COVID-19 symptom checkers. Only two out of ten symptom checkers showed a reasonably good balance between sensitivity and specificity: namely Infermedica $\left(F_{1}=0.80\right)$ and Symptoma $\left(F_{1}=0.92\right)$. Most other checkers are either too sensitive, classifying almost all patients as COVID-19 positive, or too specific, classifying many COVID-19 patients as COVID-19 negative (see Fig 1). For example, our BMJ control cases contain a patient suffering from a pulmonary disease who presents with various symptoms, including fever, cough and shortness of breath, the three most frequent symptoms associated with COVID-19. Symptoma uses the additional symptoms and risk factors not considered by the other checkers, namely loss of appetite, green sputum, and a history of smoking, to discern the correct diagnosis of COVID-19 negative. Five of the other checkers consider this case as high risk.

Furthermore, most of the symptom checkers are even out-performed by our simplistic symptom frequency vector approaches (SF-DIST $\left(F_{1}=0.57\right)$ and SF-COS $\left(F_{1}=0.79\right)$ ). Notably, the cosine version shows surprisingly good results outperforming 8 out of 10 symptom checkers based on the $F_{1}$ score.

To our knowledge this is the first scientific evaluation of online COVID-19 symptom checkers, however, there are a number of related studies evaluating symptom checkers. These include a study that evaluated 23 general-purpose symptom checkers 
medRxiv preprint doi: https://doi.org/10.1101/2020.05.22.20109777; this version posted August 19, 2020. The copyright holder for this preprint (which was not certified by peer review) is the author/funder, who has granted medRxiv a license to display the preprint in It is made available under a CC-BY-NC-ND 4.0 International license .

based on 45 clinical case descriptions across a wide range of medical conditions and found that the correct diagnosis was on average listed among the top 20 results of the checkers in $58 \%$ of all cases [2]. This study design was extended for five additional symptom checkers using ear, nose and throat (ENT) cases showing similar results [8]. Other evaluations include symptom checkers used for knee pain cases that found, based on 527 patients and 26 knee problems, that the physician's diagnosis was present within the prediction list in $89 \%$ of the cases while the specificity was only $27 \%$ [9]. In another study, an analysis of a university students' automated self-assessment triage system prior to an in-person consultation with a medical doctor found that the system's urgency rating agreed perfectly in only $39 \%$ of cases while for the remaining cases the system tended to be more risk averse than the doctor [10]. Also, the applicability of online symptom checkers for 79 persons aged $\geq 50$ years based on "think-aloud" protocols [11], deep learning algorithms for medical imaging [12], and services for urgent care [3] were evaluated.

If the performance of any (COVID-19) online symptom checker is acceptable depends on the perspective and use of the results. In the case of COVID-19, an online assessment can not fully replace a PCR-test as some people are asymptomatic, while others presenting with very specific COVID-19 symptoms might, in fact, have a very similar but different disease. Regardless, online COVID-19 symptom checkers can act as a first triage shield to take pressure off from in-person physician visits or hospitals. Symptom checkers could even replace telephone triage lines in which non-medically trained personnel read a predefined sequence of questions. Even though this was not part of 
medRxiv preprint doi: https://doi.org/10.1101/2020.05.22.20109777; this version posted August 19, 2020. The copyright holder for this preprint (which was not certified by peer review) is the author/funder, who has granted medRxiv a license to display the preprint in It is made available under a CC-BY-NC-ND 4.0 International license .

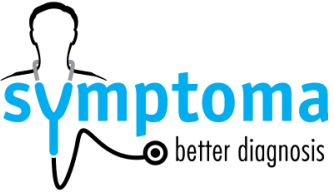

\section{A benchmark of online COVID-19 symptom checkers}

this study, the authors believe that COVID-19 symptom checkers (if appropriately maintained and tested) might also be more reliable than the direct use of search engines such as Google or information via social media.

The strength of this study lies in the fact that it is based on a large number $(n=460)$ of real patients' case descriptions from the literature and a detailed evaluation on the best performing symptom checker ( Fig 2 $)$. Vice versa, a potential weakness of this study lies in using real literature-based cases, which might have biased the test set to rather severe cases of COVID-19, as mild and uninteresting cases are usually not found in the literature. We countered this bias by not including extreme edge cases from the literature into our 50 COVID-19 cases. Another bias might be that our control case descriptions do not report a "COVID-19 contact", even though a person with, for example a cold, might have had a COVID-19 contact (and did not get infected). Another limit of this study is the non-straight forward mapping of the symptom checker outputs to risk levels (S5 Table). The interpretation of the textual output is debatable in some cases. We countered this by allowing three different risk levels and merging them together in two different ways (see Fig 1A and Fig 1B). We also classified every symptom checker output by multiple persons until consensus was reached.

\section{Conclusion}

Symptom checkers are being widely used in response to the COVID-19 global pandemic. As such, quality assessment of these tools is critical. We show that various online COVID-19 symptom checkers vary widely in their predictive capabilities, with some 
medRxiv preprint doi: https://doi.org/10.1101/2020.05.22.20109777; this version posted August 19, 2020. The copyright holder for this preprint (which was not certified by peer review) is the author/funder, who has granted medRxiv a license to display the preprint in It is made available under a CC-BY-NC-ND 4.0 International license.

\section{SVmptoma \\ A benchmark of online COVID-19 symptom checkers}

performing equivalently to randomly guessing, while others, namely Symptoma

$\left(F_{1}=0.92\right)$ and Infermedica $\left(F_{1}=0.80\right)$, exhibiting high accuracy.

\section{Contributors}

Study design: BK, AM, JN, NM. Data compilation: SG, NM, RW, IA. Data analysis: NM, AM, BK, IA, RW. Writing the manuscript: BK, NM. Revising the manuscript critically: AM, BK, SG, JN.

\section{Declaration of interests}

All authors are employees of Symptoma $\mathrm{GmbH}$. JN holds shares of Symptoma.

\section{Acknowledgments}

This study has received funding from the European Union's Horizon 2020 research and innovation programme under grant agreement No 830017. 
medRxiv preprint doi: https://doi.org/10.1101/2020.05.22.20109777; this version posted August 19, 2020. The copyright holder for this preprint (which was not certified by peer review) is the author/funder, who has granted medRxiv a license to display the preprint in It is made available under a CC-BY-NC-ND 4.0 International license .

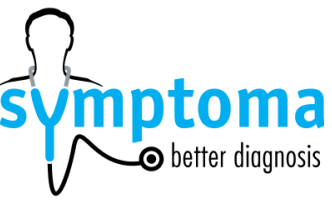

\section{A benchmark of online COVID-19 symptom checkers}

\section{References}

1. Tasnim S, Hossain M, Mazumder $\mathrm{H}$. Impact of rumors or misinformation on coronavirus disease (COVID-19) in social media. : 8.

2. Semigran HL, Linder JA, Gidengil C, Mehrotra A. Evaluation of symptom checkers for self diagnosis and triage: audit study. BMJ. 2015; h3480. doi:10.1136/bmj.h3480

3. Chambers D, Cantrell A, Johnson M, Preston L, Baxter SK, Booth A, et al. Digital and online symptom checkers and assessment services for urgent care to inform a new digital platform: a systematic review. Southampton (UK): NIHR Journals Library; 2019. Available: http://www.ncbi.nlm.nih.gov/books/NBK545124/

4. I asked eight chatbots whether I had Covid-19. The answers ranged from 'low' risk to 'start home isolation.' Available:

https://www.statnews.com/2020/03/23/coronavirus-i-asked-eight-chatbots-whetheri-had-covid-19/

5. Report of the WHO-china joint mission on coronavirus disease 2019 (covid-19). 2020. Available:

https://www.who.int/docs/default-source/coronaviruse/who-china-joint-mission-oncovid-19-final-report.pdf

6. BMJ best practice. 2020. Available: https://bestpractice.bmj.com/info/

7. BMJ case reports. 2020. Available: https://casereports.bmj.com

8. Nateqi J, Lin S, Krobath H, Gruarin S, Lutz T, Dvorak T, et al. [From symptom to diagnosis-symptom checkers re-evaluated: Are symptom checkers finally sufficient and accurate to use? An update from the ENT perspective]. HNO. 2019;67: 334-342. doi:10.1007/s00106-019-0666-y

9. Bisson LJ, Komm JT, Bernas GA, Fineberg MS, Marzo JM, Rauh MA, et al. Accuracy of a Computer-Based Diagnostic Program for Ambulatory Patients With Knee Pain. Am J Sports Med. 2014;42: 2371-2376. doi:10.1177/0363546514541654

10. Poote AE, French DP, Dale J, Powell J. A study of automated self-assessment in a primary care student health centre setting. J Telemed Telecare. 2014;20: 123-127. doi:10.1177/1357633X14529246

11. Luger TM, Houston TK, Suls J. Older adult experience of online diagnosis: results from a scenario-based think-aloud protocol. J Med Internet Res. 2014;16: e16. doi:10.2196/jmir.2924

12. Nagendran M, Chen $Y$, Lovejoy CA, Gordon AC, Komorowski M, Harvey $H$, et al. Artificial intelligence versus clinicians: systematic review of design, reporting standards, and claims of deep learning studies. BMJ. 2020;368.

doi:10.1136/bmj.m689 
medRxiv preprint doi: https://doi.org/10.1101/2020.05.22.20109777; this version posted August 19, 2020. The copyright holder for this preprint (which was not certified by peer review) is the author/funder, who has granted medRxiv a license to display the preprint in It is made available under a CC-BY-NC-ND 4.0 International license

\section{Symptoma}

\section{A benchmark of online COVID-19 symptom checkers}

\section{Supporting information}

S1 Table. Symptom frequencies used in S2 Text.

\begin{tabular}{|c|c|c|c|c|c|}
\hline & COVID-19 & Common cold & Influenza & Hay fev & rer \\
\hline Fever & $87.9[1]$ & 15 [3] & $68 \quad[6]$ & & NR \\
\hline Fatique & 38.1 [2] & $42 \quad[4]$ & 94 [6] & & NR \\
\hline Dry cough & $67.7 \quad[1]$ & $80 \quad[3]$ & 93 [6] & 22 & [10] \\
\hline Sneezing & NR & $74 \quad[4]$ & $58 \quad[7]$ & 96 & [11] \\
\hline Malaise & $14.8 \quad[1]$ & $30 \quad[4]$ & 94 [6] & & NR \\
\hline Rhinorrhea & $4 \quad[2]$ & 95 [3] & 91 [6] & 62.1 & [12] \\
\hline Sore throat & $13.9[1]$ & $70 \quad[3]$ & $84 \quad[6]$ & 30 & [10] \\
\hline Diarrhea & $3.7[1]$ & $11[4]$ & 14.4 [8] & & NR \\
\hline Headache & $13.6[1]$ & $80 \quad[5]$ & 91 [6] & 50 & [13] \\
\hline Dyspnea & 18.6 [1] & $21 \quad[4]$ & 63 [9] & & NR \\
\hline
\end{tabular}

\begin{tabular}{|c|c|}
\hline Number & URL \\
\hline [1] & $\begin{array}{l}\text { https://www.who.int/docs/default-source/coronaviruse/who-china-joint-mission-on-covid-19-final-report.pdf\&sa=D\&ust=1585147724205000\&us } \\
\text { g=AFQjCNHMTMLZYuYavNS7iXN_D8AaJvOYiw }\end{array}$ \\
\hline [2] & https:/www.thelancet.com/action/showPdPpii=50140-6736\%2820962930211-7 \\
\hline [3] & https:/www.sciencedirect.com/science/article/pii/500954543057035597via93Dihub \\
\hline [4] & https://www.ncbi.nlm.nih.gov/pubmed/3057962 \\
\hline [5] & https:/Wwww.ncbi.nlm.nih.gov/pmc/articles/PMC4347877/pdf/nihms658637.pdf \\
\hline [6] & https://jamanetwork.com/journals/jamainternalmedicine/fullarticle/485554 \\
\hline [7] & https://www.ncbi.nlm.nih.gov/pmc/articles/PMC4915903/ \\
\hline [8] & https:/Www.ncbi.nlm.nih.gov/pme/articles/PMC4676820/ \\
\hline [9] & https:/wwnw.ncbi.nlm.nih.gov/pme/articles/PMC3650195/ \\
\hline [10] & https://wwow.ncbi.nlm.nih.gov/pubmed/10971479 \\
\hline [11] & https://wWw.ncbi.nlm.nih.gov/pmc/articles/PMC5806744/ \\
\hline [12] & $\begin{array}{l}\text { https://www.researchgate.net/publication/307953143_Inverse_correlation_of_soluble_programmed_cell_death-1_ligand-1_SPD-L1_with_eosinoph } \\
\text { il_count_and_clinical_severity_in_allergic_rhinitis_patients }\end{array}$ \\
\hline [13] & https:/wwww.ncbi.nlm.nih.gov/pubmed/17300360 \\
\hline
\end{tabular}


medRxiv preprint doi: https://doi.org/10.1101/2020.05.22.20109777; this version posted August 19, 2020. The copyright holder for this preprint (which was not certified by peer review) is the author/funder, who has granted medRxiv a license to display the preprint in It is made available under a CC-BY-NC-ND 4.0 International license

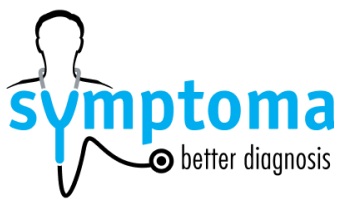

\section{A benchmark of online COVID-19 symptom checkers}

\begin{tabular}{|c|c|c|c|c|c|}
\hline case & assessor & age & sex & symptoms & Source \\
\hline 1 & 1 & 50 & FEMALE & Fever, Diarrhea, Anorexia, Asthenia, Dry Cough, Myalgia, China & 1 \\
\hline 1 & 2 & 50 & FEMALE & $\begin{array}{l}\text { Stay in COVID-19 Risk Area, Wuhan, fever, diarrhea, asthenia, } \\
\text { anorexia, dry cough, myalgia, C-reactive protein increased, ground } \\
\text { glass opacity (CT) }\end{array}$ & 1 \\
\hline 1 & 3 & 50 & FEMALE & $\begin{array}{l}\text { fever, diarrhea, anorexia, asthenia, Covid-19 risk area, dry cough, } \\
\text { muscle ache, increased CRP, ground glass opacities, consolidation }\end{array}$ & 1 \\
\hline 2 & 1 & 10 & FEMALE & $\begin{array}{l}\text { Contact COVID-19 Case, Fever, Sputum Production, consolidations, } \\
\text { Ground Glass Opacities (CT) }\end{array}$ & 2 \\
\hline 2 & 2 & 10 & FEMALE & $\begin{array}{l}\text { contact Covid-19 patient, fever, sputum production , consolidations, } \\
\text { ground glass opacities }\end{array}$ & 2 \\
\hline 2 & 3 & 10 & FEMALE & $\begin{array}{l}\text { Contact COVID-19 Case, fever, sputum production, patchy } \\
\text { consolidation, ground glass opacity }\end{array}$ & 2 \\
\hline 3 & 1 & 33 & FEMALE & $\begin{array}{l}\text { Wuhan, Fever, Cough, coarse breath sounds, Leukopenia, C-Reactive } \\
\text { Protein Increased, Elevated Sedimentation Rate, D-Dimer Abnormal, } \\
\text { Ground Glass Opacities (CT) }\end{array}$ & 3 \\
\hline 3 & 2 & 33 & FEMALE & $\begin{array}{l}\text { fever, cough, Stay in COVID-19 Risk Area, Wuhan, leukopenia, coarse } \\
\text { breath sounds, elevated C-reactive protein, Elevated Sedimentation } \\
\text { Rate, D-Dimer Abnormal, peripheral ground-glass opacitiy on CT }\end{array}$ & 3 \\
\hline 3 & 3 & 33 & FEMALE & $\begin{array}{l}\text { fever, cough, Wuhan, coarse breath sounds, leucopenia, increased } \\
\text { CRP, increased erythrocyte sedimentation rate, increased D-dimer, } \\
\text { ground glass opacities }\end{array}$ & 3 \\
\hline 4 & 1 & 41 & FEMALE & Wuhan, Fever, Ground Glass Opacities (CT) & 4 \\
\hline 4 & 2 & 41 & FEMALE & Wuhan, Stay in COVID-19 Risk Area, fever, ground-glass opacity on CT & 4 \\
\hline 4 & 3 & 41 & FEMALE & Wuhan, fever, ground glass opacities & 4 \\
\hline
\end{tabular}


medRxiv preprint doi: https://doi.org/10.1101/2020.05.22.20109777; this version posted August 19, 2020. The copyright holder for this preprint (which was not certified by peer review) is the author/funder, who has granted medRxiv a license to display the preprint in perpetuity.

It is made available under a CC-BY-NC-ND 4.0 International license .

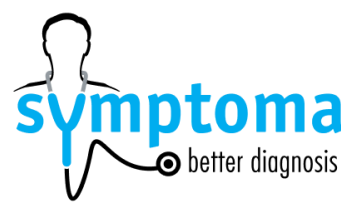

\section{A benchmark of online COVID-19 symptom checkers}

\begin{tabular}{|c|c|c|c|c|c|}
\hline 5 & 1 & 32 & MALE & $\begin{array}{l}\text { Wuhan, Fever, coarse breath sounds, Interleukin-6 Increased, right } \\
\text { lower lobe consolidation, Bronchiectasis }\end{array}$ & 5 \\
\hline 5 & 2 & 32 & MALE & $\begin{array}{l}\text { Stay in COVID-19 Risk Area, Wuhan, cough, fever, IL-6 Increased, } \\
\text { subpleural right lower lobe consolidation }\end{array}$ & 5 \\
\hline 5 & 3 & 32 & MALE & $\begin{array}{l}\text { Wuhan, cough, fever, coarse breath sounds, increased interleukin } 6 \text {, } \\
\text { bronchiectasis, subpleural right lower lobe consolidation }\end{array}$ & 5 \\
\hline 6 & 1 & 45 & FEMALE & $\begin{array}{l}\text { Wuhan, Fever, Cough, coarse breath sounds, Neutrophil Count } \\
\text { Increased, Lymphocytopenia, Elevated Sedimentation Rate, } \\
\text { Interleukin-6 Increased, peripheral consolidation, Pneumonia, } \\
\text { crazy-paving pattern }\end{array}$ & 5 \\
\hline 6 & 2 & 45 & FEMALE & $\begin{array}{l}\text { Wuhan, Stay in COVID-19 Risk Area, cough, fever, Neutrophil Count } \\
\text { Increased, lymphopenia, Elevated Sedimentation Rate, IL-6 } \\
\text { increased, bilateral peripheral consolidation }\end{array}$ & 5 \\
\hline 6 & 3 & 45 & FEMALE & $\begin{array}{l}\text { Wuhan, cough, fever, coarse breath sounds, increased neutrophil } \\
\text { ratio, decreased lymphocyte, increased erythrocyte sedimentation } \\
\text { rate, increased interleukin } 6 \text {, consolidation, interlobular septal } \\
\text { thickening, crazy paving appearance, bronchiectasis }\end{array}$ & 5 \\
\hline 7 & 1 & 42 & MALE & $\begin{array}{l}\text { High Fever, Cough, Fatigue, Bilateral coarse breath sounds, Wet } \\
\text { Rales, Leukopenia, Lymphocytes Increased, C-Reactive Protein } \\
\text { Increased, Elevated Sedimentation Rate, Amyloid A Protein } \\
\text { Increased, Aspartate Transaminase Increased, Alanine } \\
\text { Aminotransferase Increased, Ground Glass Appearance, Ground } \\
\text { Glass Opacities (CT), consolidation }\end{array}$ & 6 \\
\hline 7 & 2 & 42 & MALE & $\begin{array}{l}\text { Wuhan, Stay in COVID-19 Risk Area, high fever, cough, fatigue, } \\
\text { bilateral coarse breath sounds, wet rales, leukopenia, lymphocytosis, } \\
\text { Elevated Sedimentation Rate, C-Reactive Protein Increased, Aspartate } \\
\text { Aminotransferase Increased, Alanine Aminotransferase Increased }\end{array}$ & 6 \\
\hline
\end{tabular}


medRxiv preprint doi: https://doi.org/10.1101/2020.05.22.20109777; this version posted August 19, 2020. The copyright holder for this preprint (which was not certified by peer review) is the author/funder, who has granted medRxiv a license to display the preprint in It is made available under a CC-BY-NC-ND 4.0 International license

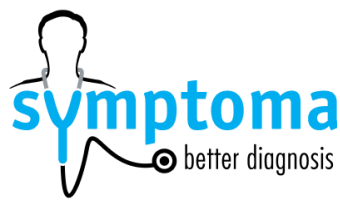

\section{A benchmark of online COVID-19 symptom checkers}

\begin{tabular}{|c|c|c|c|c|c|}
\hline 7 & 3 & 42 & MALE & $\begin{array}{l}\text { Wuhan, fever, cough, fatigue, coarse breath sounds, wet rales, } \\
\text { leukopenia, lymphocytosis, increased CRP, increased erythrocyte } \\
\text { sedimentation rate, increased serum amyloid A protein, increased } \\
\text { aspartate aminotransferase, increased alanine aminotransferase, } \\
\text { ground glass opacities, ground glass consolidation }\end{array}$ & 6 \\
\hline 8 & 1 & 63 & FEMALE & $\begin{array}{l}\text { Wuhan, Fever, Cough, Dizziness, Constipation, Tachypnea, Rhonchi, } \\
\text { Bilateral pneumonia }\end{array}$ & 7 \\
\hline 8 & 2 & 63 & FEMALE & $\begin{array}{l}\text { Wuhan, Stay in COVID-19 Risk Area, fever, cough, dizziness, } \\
\text { constipation, Hyperpnea }\end{array}$ & 7 \\
\hline 8 & 3 & 63 & FEMALE & $\begin{array}{l}\text { Wuhan, fever, cough, dizziness, constipation, tachypnea, Rhonchi, } \\
\text { pneumonia }\end{array}$ & 7 \\
\hline 9 & 1 & 63 & MALE & $\begin{array}{l}\text { Contact COVID-19 Case, Fever, Cough, Tachypnea, Rhonchi, } \\
\text { Unilateral pneumonia }\end{array}$ & 7 \\
\hline 9 & 2 & 63 & MALE & $\begin{array}{l}\text { Contact COVID-19 Case, fever, cough, hyperpnea, Abnormal Chest CT } \\
\text { Scan }\end{array}$ & 7 \\
\hline 9 & 3 & 63 & MALE & $\begin{array}{l}\text { contact Covid-19 patient, fever, cough, tachypnea, Rhonchi, } \\
\text { pneumonia }\end{array}$ & 7 \\
\hline 10 & 1 & 19 & MALE & $\begin{array}{l}\text { Wuhan, Fever, Cough, Fatigue, Nasal Congestion, Rhinorrhea, } \\
\text { Unilateral pneumonia }\end{array}$ & 7 \\
\hline 10 & 2 & 19 & MALE & $\begin{array}{l}\text { Wuhan, Stay in COVID-19 Risk Area, fever, cough, fatigue, nasal } \\
\text { congestion, rhinorrhea, Abnormal CT scan }\end{array}$ & 7 \\
\hline 10 & 3 & 19 & MALE & $\begin{array}{l}\text { fever , cough, fatigue, Nasal congestion, Rhinorrhea, pneumonia, } \\
\text { COVID-19 Risk Area }\end{array}$ & 7 \\
\hline 11 & 1 & 30 & FEMALE & Fever, Chills, Fatigue, Cough, China & 8 \\
\hline 11 & 2 & 30 & FEMALE & $\begin{array}{l}\text { Wuhan, Stay in COVID-19 Risk Area, Contact COVID-19 Case, fever, } \\
\text { chills, fatigue, cough }\end{array}$ & 8 \\
\hline
\end{tabular}


medRxiv preprint doi: https://doi.org/10.1101/2020.05.22.20109777; this version posted August 19, 2020. The copyright holder for this preprint (which was not certified by peer review) is the author/funder, who has granted medRxiv a license to display the preprint in It is made available under a CC-BY-NC-ND 4.0 International license

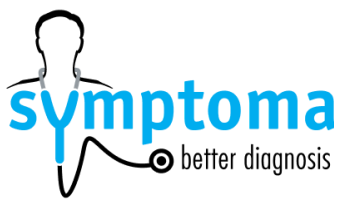

\section{A benchmark of online COVID-19 symptom checkers}

\begin{tabular}{|c|c|c|c|c|c|}
\hline 11 & 3 & 30 & FEMALE & $\begin{array}{l}\text { Covid-19 risk area, contact Covid-19 patient, fever, chills, fatigue, } \\
\text { cough }\end{array}$ & 8 \\
\hline 12 & 1 & 31 & MALE & Wuhan, Fever, Chills, Fatigue, Conjunctivitis, Cough & 8 \\
\hline 12 & 2 & 31 & MALE & $\begin{array}{l}\text { Wuhan, Stay in COVID-19 Risk Area, fever, chills, fatigue, } \\
\text { conjunctivitis }\end{array}$ & 8 \\
\hline 12 & 3 & 31 & MALE & fever, chills, fatigue, conjunctivitis, cough, Covid-19 risk area & 8 \\
\hline 13 & 1 & 48 & MALE & Wuhan, Fever, Headache, Cough & 9 \\
\hline 13 & 2 & 48 & MALE & Wuhan, Stay in COVID-19 Risk Area, fever, headache, cough & 9 \\
\hline 13 & 3 & 48 & MALE & Covid-19 risk area, fever, headache, cough & 9 \\
\hline 14 & 1 & 55 & MALE & $\begin{array}{l}\text { Wuhan, Sore Throat, Myalgia, prominent bronchovascular bundle, } \\
\text { Fever, Lymphocytopenia, C-Reactive Protein Increased, consolidation } \\
\text { of both lower lobes, Ground Glass Opacities (CT) }\end{array}$ & 10 \\
\hline 14 & 2 & 55 & MALE & $\begin{array}{l}\text { Wuhan, Stay in COVID-19 Risk Area, Contact COVID-19 Case, Fever, } \\
\text { sore throat, bilateral patchy consolidation, myalgia }\end{array}$ & 10 \\
\hline 14 & 3 & 55 & MALE & $\begin{array}{l}\text { Covid-19 risk area, sore throat, myalgia, prominent bronchovascular } \\
\text { bundle, fever, lymphopenia, increased CRP, bilateral patch } \\
\text { consolidation, ground glass opacities, interlobular septal thickening }\end{array}$ & 10 \\
\hline 15 & 1 & 50 & MALE & $\begin{array}{l}\text { Fever, Chills, Cough, Fatigue, Dyspnea, Wuhan, Leukopenia, } \\
\text { Lymphocytopenia, multiple patchy shadows in both lungs, C-Reactive } \\
\text { Protein Increased }\end{array}$ & 11 \\
\hline 15 & 2 & 50 & MALE & $\begin{array}{l}\text { fever, chills, cough, fatigue, dyspnea, Stay in COVID-19 Risk Area, } \\
\text { patchy shadow on X-ray }\end{array}$ & 11 \\
\hline 15 & 3 & 50 & MALE & $\begin{array}{l}\text { fever, chills, cough, fatigue, shortness of breath, Covid-19 risk area, } \\
\text { diffuse gridding shadow lung }\end{array}$ & 11 \\
\hline
\end{tabular}


medRxiv preprint doi: https://doi.org/10.1101/2020.05.22.20109777; this version posted August 19, 2020. The copyright holder for this preprint (which was not certified by peer review) is the author/funder, who has granted medRxiv a license to display the preprint in perpetuity.

It is made available under a CC-BY-NC-ND 4.0 International license .

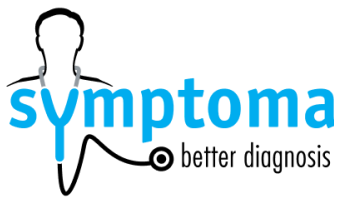

\section{A benchmark of online COVID-19 symptom checkers}

\begin{tabular}{|c|c|c|c|c|c|}
\hline 16 & 1 & 46 & FEMALE & $\begin{array}{l}\text { Fever, Sore Throat, Cough, Chest Discomfort, Wuhan, Ground Glass } \\
\text { Opacities (CT) }\end{array}$ & 12 \\
\hline 16 & 2 & 46 & FEMALE & $\begin{array}{l}\text { fever, sore throat, cough, chest distress, Stay in COVID-19 Risk Area, } \\
\text { Wuhan, ground-glass opacity on CT }\end{array}$ & 12 \\
\hline 16 & 3 & 46 & FEMALE & $\begin{array}{l}\text { fever, sore throat, cough, chest distress, Covid-19 risk area, contact } \\
\text { Covid-19 patient, ground glass opacities }\end{array}$ & 12 \\
\hline 17 & 1 & 34 & FEMALE & $\begin{array}{l}\text { Fever, history of hypothyroidism, Vaginal Bleeding, Abdominal Pain, } \\
\text { Wuhan, Ground Glass Opacities (CT), Lymphocytopenia, Neutrophil } \\
\text { Count Increased, C-Reactive Protein Increased }\end{array}$ & 13 \\
\hline 17 & 2 & 34 & FEMALE & $\begin{array}{l}\text { Wuhan, Stay in COVID-19 Risk Area, fever, ground-glass opacity on } \\
\text { CT, lymphopenia, neutrophilia, C-reactive protein increased }\end{array}$ & 13 \\
\hline 17 & 3 & 34 & FEMALE & $\begin{array}{l}\text { Covid-19 risk area, vaginal bleeding, abdominal pain, fever, ground } \\
\text { glass opacities, lymphopenia, neutrophilia, increased CRP }\end{array}$ & 13 \\
\hline 18 & 1 & 52 & MALE & $\begin{array}{l}\text { history of kidney transplantation, Immunosuppressive Therapy, } \\
\text { Wuhan, Fatigue, Dyspnea, Dull Chest Pain, Chest Pain, Nausea, Loss } \\
\text { of Appetite, Abdominal Pain, Dry Cough, Fever, Headache, } \\
\text { Lymphocytopenia, Neutrophil Count Increased, Monocyte Count } \\
\text { Increased, C-Reactive Protein Increased, Ground Glass Opacities (CT) }\end{array}$ & 14 \\
\hline 18 & 2 & 52 & MALE & $\begin{array}{l}\text { immunosuppression, Wuhan, Stay in COVID-19 Risk Area, fatigue, } \\
\text { dyspnea, chest tightness, nausea, loss of appetite, abdominal pain, } \\
\text { dry cough, fever, headache, lymphopenia, neutrophil count } \\
\text { increased, C-reactive protein increased, multiple ground-glass } \\
\text { opacity }\end{array}$ & 14 \\
\hline 18 & 3 & 52 & MALE & $\begin{array}{l}\text { chronic glomerulonephritis, immunosuppressive therapy, Covid-19 } \\
\text { risk area , fatigue, dyspnea, tightness chest, chest pain, nausea, loss } \\
\text { of appetite, abdominal pain, dry cough, fever, headache, decreased } \\
\text { lymphocytes, increased CRP, ground glass shadow, increased } \\
\text { neutrophil count }\end{array}$ & 14 \\
\hline
\end{tabular}


medRxiv preprint doi: https://doi.org/10.1101/2020.05.22.20109777; this version posted August 19, 2020. The copyright holder for this preprint (which was not certified by peer review) is the author/funder, who has granted medRxiv a license to display the preprint in It is made available under a CC-BY-NC-ND 4.0 International license

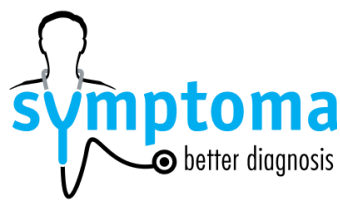

\section{A benchmark of online COVID-19 symptom checkers}

\begin{tabular}{|c|c|c|c|c|c|}
\hline 19 & 1 & 40 & FEMALE & $\begin{array}{l}\text { Fever, Dull Chest Pain, Fatigue, peripheral consolidations, } \\
\text { ground-glass opacities in both lungs }\end{array}$ & 15 \\
\hline 19 & 2 & 40 & FEMALE & $\begin{array}{l}\text { fever, chest tightness, fatigue, ground glass opacity (CT), cough, } \\
\text { leukopenia }\end{array}$ & 15 \\
\hline 19 & 3 & 40 & FEMALE & $\begin{array}{l}\text { fever, chest tightness, fatigue, glucose increased, ground glass } \\
\text { opacities, peripheral consolidations, cough, decreased leukocytes, } \\
\text { increased CRP }\end{array}$ & 15 \\
\hline 20 & 1 & 35 & MALE & $\begin{array}{l}\text { Wuhan, Fever, Cough, Neutrophil Count Increased, } \\
\text { Lymphocytopenia, Glucose Increased, Ground Glass Appearance, } \\
\text { C-Reactive Protein Increased }\end{array}$ & 16 \\
\hline 20 & 2 & 35 & MALE & $\begin{array}{l}\text { Stay in COVID-19 Risk Area, fever, cough, Wuhan, neutrophil count } \\
\text { increased, lymphopenia, C-reactive protein increased, multiple } \\
\text { patchy consolidations, ground-glass opacity (CT) }\end{array}$ & 16 \\
\hline 20 & 3 & 35 & MALE & $\begin{array}{l}\text { fever, cough, Covid-19 risk area, increased neutrophils, decreased } \\
\text { lymphocytes, elevated glucose, increased CRP, consolidation, } \\
\text { ground glass opacities }\end{array}$ & 16 \\
\hline 21 & 1 & 81 & FEMALE & Abdominal Pain, Diarrhea, Sore Throat, Diamond Princess cruise ship & 17 \\
\hline 21 & 2 & 81 & FEMALE & abdominal pain, sore throat, cruise ship, diarrhea, Japan & 17 \\
\hline 21 & 3 & 81 & FEMALE & abdominal pain, watery diarrhea, sore throat, Diamond Princess & 17 \\
\hline 22 & 1 & 35 & FEMALE & $\begin{array}{l}\text { Fever, Chills, Myalgia, Wuhan, Nasal Congestion, Cough, Sputum } \\
\text { Production }\end{array}$ & 18 \\
\hline 22 & 2 & 35 & FEMALE & $\begin{array}{l}\text { fever, chills, myalgia, Wuhan, Stay in COVID-19 Risk Area, cough, } \\
\text { nasal congestion, sputum production }\end{array}$ & 18 \\
\hline 22 & 3 & 35 & FEMALE & $\begin{array}{l}\text { Covid-19 risk area, fever, chill, myalgia, nasal congestion, cough, } \\
\text { sputum production }\end{array}$ & 18 \\
\hline 23 & 1 & 54 & MALE & Fever, Dry Cough, ground-glass opacities in both lower lobes, China & 19 \\
\hline
\end{tabular}


medRxiv preprint doi: https://doi.org/10.1101/2020.05.22.20109777; this version posted August 19, 2020. The copyright holder for this preprint (which was not certified by peer review) is the author/funder, who has granted medRxiv a license to display the preprint in It is made available under a CC-BY-NC-ND 4.0 International license

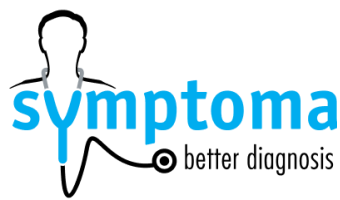

\section{A benchmark of online COVID-19 symptom checkers}

\begin{tabular}{|c|c|c|c|c|c|}
\hline 23 & 2 & 54 & MALE & $\begin{array}{l}\text { Wuhan, Stay in COVID-19 Risk Area, hypertension, fever, dry cough, } \\
\text { ground glass opacity (CT) }\end{array}$ & 19 \\
\hline 23 & 3 & 54 & MALE & $\begin{array}{l}\text { Covid-19 risk area, chills, muscle pain, hypertension, dry cough, } \\
\text { consolidation, ground glass opacities }\end{array}$ & 19 \\
\hline 24 & 1 & 39 & MALE & Fever, Sore Throat, Glucose Increased, Ground Glass Opacities (CT) & 16 \\
\hline 24 & 2 & 39 & MALE & Contact COVID-19 Case, fever, ground-glass opacity (CT) & 16 \\
\hline 24 & 3 & 39 & MALE & $\begin{array}{l}\text { fever, soar throat, contact Covid-19 patient, , decreased aspartate } \\
\text { aminotransferase, elevated glucose, ground glass opacities }\end{array}$ & 16 \\
\hline 25 & 1 & 39 & MALE & $\begin{array}{l}\text { Cough, frothy white sputum, Bilateral Pulmonary Opacities, Dyspnea, } \\
\text { Decreased Oxygen Saturation, Altered Mental Status, Wuhan }\end{array}$ & 20 \\
\hline 25 & 2 & 39 & MALE & $\begin{array}{l}\text { Wuhan, Stay in COVID-19 Risk Area, fever, cough, sputum } \\
\text { production, dyspnea, alteration of consciousness, patchy opacities } \\
\text { (CT) }\end{array}$ & 20 \\
\hline 25 & 3 & 39 & MALE & $\begin{array}{l}\text { Covid-19 risk area, fever, cough, frothy white sputum, shortness of } \\
\text { breath, patchy opacities, decreased mental state, decreased SpO2, } \\
\text { ground glass opacities, increased albumin, increased Aspartate } \\
\text { aminotransferase, increased Lactate dehydrogenase, Wuhan }\end{array}$ & 20 \\
\hline 26 & 1 & 21 & FEMALE & $\begin{array}{l}\text { Cough, Chills, Fever, frothy white sputum, Bilateral Pulmonary } \\
\text { Opacities, Wuhan }\end{array}$ & 21 \\
\hline 26 & 2 & 21 & FEMALE & $\begin{array}{l}\text { Contact COVID-19 Case, fever, cough, chills, sputum production, } \\
\text { leukopenia, thrombocytopenia }\end{array}$ & 21 \\
\hline 26 & 3 & 21 & FEMALE & $\begin{array}{l}\text { Covid-19 risk area, fever, cough, chills, frothy white sputum, patchy } \\
\text { opacities, decreased lymphocytes, decreased platelet count }\end{array}$ & 21 \\
\hline 27 & 1 & 50 & MALE & $\begin{array}{l}\text { Diabetes Mellitus, Pneumonia, Respiratory Distress, Decreased } \\
\text { Oxygen Saturation }\end{array}$ & 22 \\
\hline 27 & 2 & 50 & MALE & diabetes mellitus, hyperlipidemia, respiratory distress & 22 \\
\hline
\end{tabular}


medRxiv preprint doi: https://doi.org/10.1101/2020.05.22.20109777; this version posted August 19, 2020. The copyright holder for this preprint (which was not certified by peer review) is the author/funder, who has granted medRxiv a license to display the preprint in It is made available under a CC-BY-NC-ND 4.0 International license

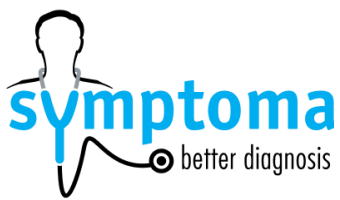

\section{A benchmark of online COVID-19 symptom checkers}

\begin{tabular}{|c|c|c|c|c|c|}
\hline 27 & 3 & 50 & MALE & diabetes mellitus, penumonia, respiratory distress & 22 \\
\hline 28 & 1 & 47 & FEMALE & $\begin{array}{l}\text { Wuhan, Lethargy, Sore Throat, Dry Cough, Pleuritic Pain, Dyspnea, } \\
\text { Fever, Bilateral Pulmonary Infiltrate, C-Reactive Protein Increased }\end{array}$ & 23 \\
\hline 28 & 2 & 47 & FEMALE & $\begin{array}{l}\text { Wuhan, lethargy, sore throat, dry cough, pleuritic chest pain, } \\
\text { dyspnea, fever, tachycardia, C-reactive protein increased, bilateraly } \\
\text { patchy infiltration }\end{array}$ & 23 \\
\hline 28 & 3 & 47 & FEMALE & $\begin{array}{l}\text { Covid-19 risk area, lethargy, sore throat, dry cough, pleuritic chest } \\
\text { pain , dyspnea, fever, rhonchi, increased CRP, pulmonary infiltrate }\end{array}$ & 23 \\
\hline 29 & 1 & 32 & MALE & $\begin{array}{l}\text { Fever, Fatigue, Dizziness, Constipation, Rhonchi , Tachypnea, Bilateral } \\
\text { pneumonia }\end{array}$ & 7 \\
\hline 29 & 2 & 32 & MALE & $\begin{array}{l}\text { fever, fatigue, dizziness, constipation, rhonchi on auscultation, } \\
\text { hyperpnea, CT scan abnormal }\end{array}$ & 7 \\
\hline 29 & 3 & 32 & MALE & $\begin{array}{l}\text { Covid-19 risk area, fever, fatigue, dizziness, Constipation, Rhonchi, } \\
\text { tachypnea, pneumonia }\end{array}$ & 7 \\
\hline 30 & 1 & 64 & MALE & $\begin{array}{l}\text { Fever, Dizziness, Headache, Malaise, Wuhan, bilateral multiple } \\
\text { ground-glass opacities }\end{array}$ & 24 \\
\hline 30 & 2 & 64 & MALE & $\begin{array}{l}\text { fever, dizziness, headache, myalgia, Wuhan, Stay in COVID-19 Risk } \\
\text { Area, ground-glass opacity }\end{array}$ & 24 \\
\hline 30 & 3 & 64 & MALE & $\begin{array}{l}\text { ground glass opacities, fever, dizziness, headache, aching limbs, } \\
\text { Covid-19 risk area }\end{array}$ & 24 \\
\hline 31 & 1 & 79 & FEMALE & $\begin{array}{l}\text { history of coronary artery disease, Hypertension, Congestive Heart } \\
\text { Failure, Syncope, Myalgia, Fever, Cough, Lymphocytopenia, Chills, } \\
\text { Ground Glass Opacities (CT) }\end{array}$ & 25 \\
\hline 31 & 2 & 79 & FEMALE & $\begin{array}{l}\text { coronary artery disease, hypertension, myalgia, cough, fever, altered } \\
\text { consciousness, lymphopenia, chills, ground-glass opacity (CT) }\end{array}$ & 25 \\
\hline 31 & 3 & 79 & FEMALE & $\begin{array}{l}\text { coronary artery disease, hypertension, myalgia, cough, fever, } \\
\text { lymphopenia, chills, ground glass opacities }\end{array}$ & 25 \\
\hline
\end{tabular}


medRxiv preprint doi: https://doi.org/10.1101/2020.05.22.20109777; this version posted August 19, 2020. The copyright holder for this preprint (which was not certified by peer review) is the author/funder, who has granted medRxiv a license to display the preprint in perpetuity.

It is made available under a CC-BY-NC-ND 4.0 International license .

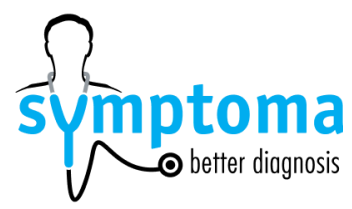

\section{A benchmark of online COVID-19 symptom checkers}

\begin{tabular}{|c|c|c|c|c|c|}
\hline 32 & 1 & 75 & MALE & $\begin{array}{l}\text { End Stage Renal Disease, Wuhan, Cough, Dull Chest Pain, } \\
\text { Hypertension, Heart Failure, Chronic Obstructive Pulmonary Disease, } \\
\text { pitting edema bilaterally, Ground Glass Opacities (CT), Decreased } \\
\text { Oxygen Saturation }\end{array}$ & 26 \\
\hline 32 & 2 & 75 & MALE & $\begin{array}{l}\text { Wuhan, Stay in COVID-19 Risk Area, end-stage kidney disease, cough, } \\
\text { chest tightness, hypertension, Chronic obstructive pulmonary } \\
\text { disease, hyperpnea }\end{array}$ & 26 \\
\hline 32 & 3 & 75 & MALE & $\begin{array}{l}\text { Covid-19 risk area, cough, chest tightness, hypertension, chronic } \\
\text { heart failure, COPD, End Stage Kidney Disease, tachypnea, pitting } \\
\text { edema, ground glass opacity, decreased oxygen saturation, CRP } \\
\text { increased, Wuhan }\end{array}$ & 26 \\
\hline 33 & 1 & 53 & FEMALE & $\begin{array}{l}\text { Fatigue, Fever, Cough, Hypotension, Alkalosis, Hypoxemia, } \\
\text { Hypocapnia, Low-Voltage Electrocardiogram, ST-segment depression } \\
\text { with T-wave inversion in lead V1 and aVR, Creatine Phosphokinase } \\
\text { Increased, C-Reactive Protein Increased, Chloride Decreased, } \\
\text { Potassium Increased, Hyponatremia, Lymphocytopenia, Hemoglobin } \\
\text { Increased, Hematocrit Increased, Erythrocytes Increased, ST } \\
\text { Elevation, Cardiac Enzymes Increased }\end{array}$ & 27 \\
\hline 33 & 2 & 53 & FEMALE & $\begin{array}{l}\text { fatigue, fever, cough, hypotension, tachycardia, C-reactive protein } \\
\text { increased }\end{array}$ & 27 \\
\hline 33 & 3 & 53 & FEMALE & $\begin{array}{l}\text { fatigue, fever, dry cough, hypotension, alkalosis, increased creatine } \\
\text { kinase, increased CRP, hyperkalemia, heart dysfunction }\end{array}$ & 27 \\
\hline 34 & 1 & 73 & FEMALE & $\begin{array}{l}\text { Diabetes Mellitus, Obesity, Chronic Kidney Insufficiency, } \\
\text { Hypertension, Congestive Heart Failure, Cough, Fever, Dyspnea, } \\
\text { Hypoxemia, Tachycardia, Respiratory Failure, Bilateral Pulmonary } \\
\text { Infiltrate }\end{array}$ & 28 \\
\hline 34 & 2 & 73 & FEMALE & cough, fever, dyspnea, hypoxemia, tachycardia, bilateral infiltrates CT & 28 \\
\hline
\end{tabular}


medRxiv preprint doi: https://doi.org/10.1101/2020.05.22.20109777; this version posted August 19, 2020. The copyright holder for this preprint (which was not certified by peer review) is the author/funder, who has granted medRxiv a license to display the preprint in perpetuity.

It is made available under a CC-BY-NC-ND 4.0 International license .

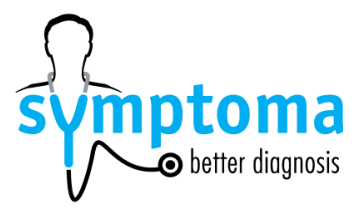

\section{A benchmark of online COVID-19 symptom checkers}

\begin{tabular}{|c|c|c|c|c|c|}
\hline 34 & 3 & 73 & FEMALE & $\begin{array}{l}\text { coronary artery disease, hypertension, congestive heart failure, } \\
\text { cough, fever, shortness of breath, tachycardia, respiratory failure, } \\
\text { bilateral infiltrates, diabetes mellitus, hypoxemia, chronic kidney } \\
\text { disease }\end{array}$ & 28 \\
\hline 35 & 1 & 38 & MALE & $\begin{array}{l}\text { Fever, Lymphocytopenia, Cough, Decreased Oxygen Saturation, Dull } \\
\text { Chest Pain, Palpitations, Dyspnea, Hypoxemia, Ground Glass } \\
\text { Opacities (CT), consolidation, Acute Respiratory Distress Syndrome, } \\
\text { Pulmonary Emphysema }\end{array}$ & 29 \\
\hline 35 & 2 & 38 & MALE & $\begin{array}{l}\text { Wuhan, Stay in COVID-19 Risk Area, fever, lymphopenia, cough, } \\
\text { hypoxemia, chest tightness, dyspnea, Ground Glass Opacities (CT) }\end{array}$ & 29 \\
\hline 35 & 3 & 38 & MALE & $\begin{array}{l}\text { Covid-19 risk area, hearing loss, tinnitus, fever, decreased } \\
\text { lymphocytes, cough, decreased oxygen saturation, chest tightness, } \\
\text { dyspnea, hypoxemia, ground glass opacities, pulmonary lesion, } \\
\text { consolidation }\end{array}$ & 29 \\
\hline 36 & 1 & 51 & MALE & $\begin{array}{l}\text { Italy, Fever, Cough, Myalgia, Malaise, Sinusitis, Sputum Production, } \\
\text { bilateral scleral injection, Hypertension, Lymphocytopenia }\end{array}$ & 30 \\
\hline 36 & 2 & 51 & MALE & $\begin{array}{l}\text { fever, cough, Stay in COVID-19 Risk Area, myalgia, malaise, sputum } \\
\text { production }\end{array}$ & 30 \\
\hline 36 & 3 & 51 & MALE & $\begin{array}{l}\text { fever , cough, myalgia, malaise, sinusitis, sputum production, } \\
\text { Covid-19 risk area, hypertension }\end{array}$ & 30 \\
\hline 37 & 1 & 39 & MALE & $\begin{array}{l}\text { history of non-Hodgkin lymphoma, history of chronic lymphocytic } \\
\text { leukaemia, China, Fever, Sore Throat, Productive Cough, Dyspnea, } \\
\text { Leukocytes Increased, Lymphocytes Increased, Hemoglobin } \\
\text { Decreased, Decreased Platelet Count, C-Reactive Protein Increased, } \\
\beta 2 \text {-microglobulin increased, Lactate Dehydrogenase Increased, } \\
\text { Immunoglobulins Decreased or Undetectable, Ground Glass } \\
\text { Opacities (CT), Pleural Effusion }\end{array}$ & 31 \\
\hline
\end{tabular}


medRxiv preprint doi: https://doi.org/10.1101/2020.05.22.20109777; this version posted August 19, 2020. The copyright holder for this preprint (which was not certified by peer review) is the author/funder, who has granted medRxiv a license to display the preprint in It is made available under a CC-BY-NC-ND 4.0 International license

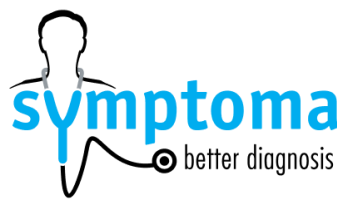

\section{A benchmark of online COVID-19 symptom checkers}

\begin{tabular}{|c|c|c|c|c|c|}
\hline 37 & 2 & 39 & MALE & $\begin{array}{l}\text { Stay in COVID-19 Risk Area, non-Hodgkin Lymphoma, fever, sore } \\
\text { throat, productive cough, dyspnea, immunosupression, } \\
\text { lymphocytosis, thrombocytopenia, C-reactive protein increased, } \\
\text { Ground Glass Opacities (CT) }\end{array}$ & 31 \\
\hline 37 & 3 & 39 & MALE & $\begin{array}{l}\text { non-Hodgkin lymphoma, chronic lymphocytic leukaemia, fever, sore } \\
\text { throat, productive cough, dyspnoea, increased CRP, lymphocytosis, } \\
\text { thrombocytopenia, increased leukocytes, increased lactate } \\
\text { dehydrogenase, decreased platelet count, ground glass opacities, } \\
\text { Covid-19 risk area, China }\end{array}$ & 31 \\
\hline 38 & 1 & & MALE & $\begin{array}{l}\text { Fever, Lethargy, cutaneous mottling, Respiratory Distress, Contact } \\
\text { COVID-19 Case }\end{array}$ & 32 \\
\hline 38 & 2 & & MALE & fever, lethargy, respiratory distress & 32 \\
\hline 38 & 3 & & MALE & $\begin{array}{l}\text { fever, lethargy, cutaneous mottling, respiratory distress, tachycardia, } \\
\text { tachypnoea, contact Covid-19 patient, Iran }\end{array}$ & 32 \\
\hline 39 & 1 & 27 & FEMALE & $\begin{array}{l}\text { Contact COVID-19 Case, Fever, Myalgia, Cough, Lymphocytopenia, } \\
\text { C-Reactive Protein Increased, Pneumonia }\end{array}$ & 33 \\
\hline 39 & 2 & 27 & FEMALE & $\begin{array}{l}\text { Contact COVID-19 Case, fever, myalgia, cough, C-reactive protein } \\
\text { increased, CT scan abnormal }\end{array}$ & 33 \\
\hline 39 & 3 & 27 & FEMALE & $\begin{array}{l}\text { contact Covid-19 patient, fever, myalgia, cough, lymphocytopenia, } \\
\text { increased CRP, pneumonia }\end{array}$ & 33 \\
\hline 40 & 1 & 26 & FEMALE & $\begin{array}{l}\text { Contact COVID-19 Case, Fever, Myalgia, Malaise, Cough, Sore Throat, } \\
\text { Lymphocytopenia, C-Reactive Protein Increased, Pneumonia }\end{array}$ & 33 \\
\hline 40 & 2 & 26 & FEMALE & $\begin{array}{l}\text { Contact COVID-19 Case, fever, myalgia, malaise, cough, sore throat, } \\
\text { lymphopenia, C-reactive protein increased, CT scan abnormal }\end{array}$ & 33 \\
\hline 40 & 3 & 26 & FEMALE & $\begin{array}{l}\text { contact Covid-19 patient, fever, myalgia, malaise, cough, sore throat, } \\
\text { Lymphopenia, increased CRP, pneumonia }\end{array}$ & 33 \\
\hline
\end{tabular}


medRxiv preprint doi: https://doi.org/10.1101/2020.05.22.20109777; this version posted August 19, 2020. The copyright holder for this preprint (which was not certified by peer review) is the author/funder, who has granted medRxiv a license to display the preprint in It is made available under a CC-BY-NC-ND 4.0 International license

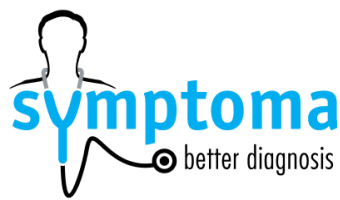

\section{A benchmark of online COVID-19 symptom checkers}

\begin{tabular}{|c|c|c|c|c|c|}
\hline 41 & 1 & 61 & MALE & $\begin{array}{l}\text { Fever, Dry Cough, Dyspnea, feeling very tired, Malaise, Hypertension, } \\
\text { Tachycardia, Chest x-ray shows bilateral lung infiltrates, Ground } \\
\text { Glass Opacities (CT), Respiratory Distress }\end{array}$ & 34 \\
\hline 41 & 2 & 61 & MALE & $\begin{array}{l}\text { fever, dry cough, dyspnea, fatigue, malaise, hypertension, } \\
\text { tachycardia, ground-glass opacity on CT, respiratory distress }\end{array}$ & 34 \\
\hline 41 & 3 & 61 & MALE & $\begin{array}{l}\text { fever, dry cough, difficulty breathing, fatigue, malaise, bilateral lung } \\
\text { infiltrates, ground glass opacity, respiratory distress, hypertension }\end{array}$ & 34 \\
\hline 42 & 1 & 26 & FEMALE & Sore Throat, Dry Cough & 34 \\
\hline 42 & 2 & 26 & FEMALE & sore throat, dry cough & 34 \\
\hline 42 & 3 & 26 & FEMALE & sore throat, dry cough & 34 \\
\hline 43 & 1 & & UNKNOWN & $\begin{array}{l}\text { Fever, Sore Throat, Myalgia, ground glass opacity of inferior lobe of } \\
\text { left lung }\end{array}$ & 35 \\
\hline 43 & 2 & & UNKNOWN & fever, sore throat, myalgia, ground-glass opacity on CT & 35 \\
\hline 43 & 3 & & UNKNOWN & fever, sore throat, muscle pain, ground glass opacity & 35 \\
\hline 44 & 1 & & UNKNOWN & $\begin{array}{l}\text { multiple patchy ground glass opacity in both lungs, effusion on both } \\
\text { lungs, Fever, Dry Cough, Productive Cough, Headache, Fatigue }\end{array}$ & 35 \\
\hline 44 & 2 & & UNKNOWN & $\begin{array}{l}\text { Fever, dry cough, productive cough, headache, fatigue, ground-glass } \\
\text { opacity on CT }\end{array}$ & 35 \\
\hline 44 & 3 & & UNKNOWN & $\begin{array}{l}\text { fever, dry cough, productive cough, headache, fatigue, ground glass } \\
\text { opacity, effusion on both lungs }\end{array}$ & 35 \\
\hline 45 & 1 & & UNKNOWN & Fever, multiple patchy ground glass opacity on both lungs & 35 \\
\hline 45 & 2 & & UNKNOWN & ground-glass opacity on CT, Fever & 35 \\
\hline 45 & 3 & & UNKNOWN & fever, CT ground glass opacity & 35 \\
\hline
\end{tabular}


medRxiv preprint doi: https://doi.org/10.1101/2020.05.22.20109777; this version posted August 19, 2020. The copyright holder for this preprint (which was not certified by peer review) is the author/funder, who has granted medRxiv a license to display the preprint in perpetuity.

It is made available under a CC-BY-NC-ND 4.0 International license .

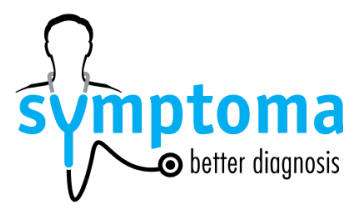

\section{A benchmark of online COVID-19 symptom checkers}

\begin{tabular}{|c|c|c|c|c|c|}
\hline 46 & 1 & & UNKNOWN & $\begin{array}{l}\text { multiple patchy ground glass opacity on both lungs, Fever, Sore } \\
\text { Throat, Dry Cough, Headache, Fatigue }\end{array}$ & 35 \\
\hline 46 & 2 & & UNKNOWN & $\begin{array}{l}\text { Fever, Sore throat, dry cough, headache, fatigue, ground-glass } \\
\text { opacity on CT }\end{array}$ & 35 \\
\hline 46 & 3 & & UNKNOWN & fever, sore throat, dry cough, headache, fatigue, ground glass opacity & 35 \\
\hline 47 & 1 & 32 & MALE & $\begin{array}{l}\text { Diarrhea, Fatigue, Cough, Dyspnea, Wuhan, foamy sputum, } \\
\text { Tachypnea, Leukocytes Increased, Neutrophil Count Increased, } \\
\text { Lymphocytopenia, C-Reactive Protein Increased, Elevated } \\
\text { Sedimentation Rate, Glucose Increased, Alanine Aminotransferase } \\
\text { Increased, Aspartate Aminotransferase Increased, Blood Urea } \\
\text { Nitrogen Increased, procalcitonin increased, diffuse multiple patchy } \\
\text { exudates, Ground Glass Opacities (CT), Hypercapnia, Hypoxemia, } \\
\text { Base Deficit, HCO3- decreased, Lactate Increased, Acidosis, } \\
\text { Thrombocytosis }\end{array}$ & 36 \\
\hline 47 & 2 & 32 & MALE & $\begin{array}{l}\text { diarrhea, fatigue, dyspnea, Wuhan, hyperpnea, leukocytosis, } \\
\text { neutrophil count increased, lymphocyte count increased, C-reactive } \\
\text { protein increased, Erythrocyte sedimentation rate increased, alanine } \\
\text { aminotransferase increased, aspartate aminotransferase increased, } \\
\text { ground-glass opacities on CT }\end{array}$ & 36 \\
\hline 47 & 3 & 32 & MALE & $\begin{array}{l}\text { diarrhea, fatigue, cough, dyspnea, Wuhan, sputum production, } \\
\text { tachypnea, increased leucocytes, increased neutrophil count, } \\
\text { increased lymphocyte count, increased CRP, increased erythrocyte } \\
\text { sedimentation rate, increased glucose, increased alanine } \\
\text { aminotransferase, increased aspartate aminotransferase, increased } \\
\text { blood urea nitrogen, increased procalcitonin, multiple patchy } \\
\text { exudates, acidosis, decreased PO2, increased PCO2, ground glass } \\
\text { opacities }\end{array}$ & 36 \\
\hline
\end{tabular}


medRxiv preprint doi: https://doi.org/10.1101/2020.05.22.20109777; this version posted August 19, 2020. The copyright holder for this preprint (which was not certified by peer review) is the author/funder, who has granted medRxiv a license to display the preprint in perpetuity.

It is made available under a CC-BY-NC-ND 4.0 International license .

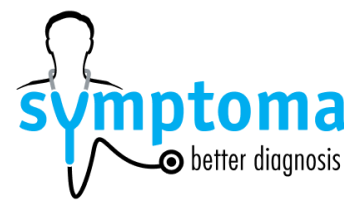

\section{A benchmark of online COVID-19 symptom checkers}

\begin{tabular}{|c|c|c|c|c|c|}
\hline 48 & 1 & 48 & MALE & $\begin{array}{l}\text { Smoking, Diabetes Mellitus, Chronic Obstructive Pulmonary Disease, } \\
\text { Fever, Cough, foamy sputum, Leukocytes Increased, } \\
\text { Lymphocytopenia, Neutrophil Count Increased, Lactate Increased, } \\
\text { Alanine Aminotransferase Increased, Bilirubin Increased, Plasma } \\
\text { Fibrinogen Increased, Fibrin Degradation Products Increased, } \\
\text { C-Reactive Protein Increased, Immunoglobulin G Increased, diffuse } \\
\text { multiple patchy exudates with partial interlobar septation, } \\
\text { Hypoxemia, Hypercapnia }\end{array}$ & 36 \\
\hline 48 & 2 & 48 & MALE & $\begin{array}{l}\text { smoking, Chronic obstructive pulmonary disease, fever, productive } \\
\text { cough, chills, diabetes mellitus, patchy exudates on CT, leukocytosis, } \\
\text { neutrophil count increased, lactate dehydrogenase increased, } \\
\text { alanine aminotransferase increased, fibrinogen increased, C-reactive } \\
\text { protein increased }\end{array}$ & 36 \\
\hline 48 & 3 & 48 & MALE & $\begin{array}{l}\text { fever, cough, shivering, sputum production, leukocytes increased, } \\
\text { lymphocytes decreased, neutrophil count increased, lactate } \\
\text { increased, increased Alanine aminotransferase, bilirubin increased, } \\
\text { LDH increased, fibrinogen increased, CRP increased, } \\
\text { Immunoglobulin G decreased, smoker, Diabetes mellitus, COPD }\end{array}$ & 36 \\
\hline 49 & 1 & 82 & FEMALE & $\begin{array}{l}\text { Tachypnea, Diarrhea, Contact COVID-19 Case, Loss of Appetite, } \\
\text { Abdominal Distension, Decreased Oxygen Saturation, Coarse Rales, } \\
\text { Alkalosis, Leukocytes Decreased, Lymphocytopenia, Neutrophil } \\
\text { Count Decreased, Decreased Platelet Count, C-Reactive Protein } \\
\text { Increased, Immunoglobulin G Increased, Hypoxemia, decreased } \\
\text { HCO3-, bilateral ground glass opacities, peripheral exudative } \\
\text { changes }\end{array}$ & 36 \\
\hline 49 & 2 & 82 & FEMALE & $\begin{array}{l}\text { Contact covid-19 case, abdominal pain, tachypnea, leukopenia, } \\
\text { lymphopenia, neutropenia, ground-glass opacities on CT, } \\
\text { thrombocytopenia }\end{array}$ & 36 \\
\hline
\end{tabular}


medRxiv preprint doi: https://doi.org/10.1101/2020.05.22.20109777; this version posted August 19, 2020. The copyright holder for this preprint (which was not certified by peer review) is the author/funder, who has granted medRxiv a license to display the preprint in It is made available under a CC-BY-NC-ND 4.0 International license.

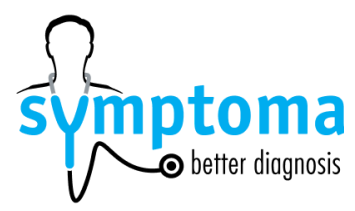

\section{A benchmark of online COVID-19 symptom checkers}

\begin{tabular}{|c|c|c|c|c|c|}
\hline 49 & 3 & 82 & FEMALE & $\begin{array}{l}\text { contact Covid-19 patient, Diarrhea, Nausea, decreased leukocytes, } \\
\text { decreased lymphocytes, decreased Neutrophil count, Platelet count } \\
\text { decreased, CRP increased, ground glass opacity, loss of appetite, } \\
\text { abdominal distension, decreased oxygen saturation , tachypnea, } \\
\text { alkalosis, decreased PaO2, HCO3- decreased }\end{array}$ & 36 \\
\hline 50 & 1 & 60 & MALE & $\begin{array}{l}\text { Hypertension, Nausea, Vomiting, Diarrhea, Fever, Dyspnea, } \\
\text { Thrombocytopenia, bilateral parenchymal opacities, basal pleural } \\
\text { effusions, Tachypnea, Hypoxemia }\end{array}$ & 37 \\
\hline 50 & 2 & 60 & MALE & $\begin{array}{l}\text { Italy, hypertension, nausea, vomiting, diarrhea, fever, dyspnea, } \\
\text { thrombocytopenia, bilateral parenchymal opacities on X-ray }\end{array}$ & 37 \\
\hline 50 & 3 & 60 & MALE & $\begin{array}{l}\text { Italy , hypertension, Nausea, vomiting, diarrhoea, fever, dyspnoea, } \\
\text { thrombocytopenia, bilateral parenchymal opacities, pleural effusions }\end{array}$ & 37 \\
\hline
\end{tabular}

\begin{tabular}{|r|l|}
\hline Source & URL \\
\hline 1 & $\underline{\text { http://balkanmedicaljournal.org/uploads/pdf/pdf BM] 2192.pdf }}$ \\
\hline 2 & $\underline{\text { https://jkms.org/DOlx.php?id=10.3346/jkms.2020.35.e124 }}$ \\
\hline 3 & $\begin{array}{l}\text { https://pubs.rsna.org/doi/10.1148/radiol.2020200236?url ver=Z39.88-2003\&rfr id=ori:ri } \\
\text { d:crossref.org\&rfr dat=cr pub\%3dpubmed }\end{array}$ \\
\hline 4 & $\begin{array}{l}\text { https://pubs.rsna.org/doi/10.1148/radiol.2020200257?url ver=Z39.88-2003\&rfr id=ori:ri } \\
\text { d:crossref.org\&rfr dat=cr pub\%3dpubmed }\end{array}$ \\
\hline 5 & $\begin{array}{l}\text { https://pubs.rsna.org/doi/10.1148/radiol.2020200280?url ver=Z39.88-2003\&rfr id=ori:ri } \\
\text { d:crossref.org\&rfr dat=cr pub\%3dpubmed }\end{array}$ \\
\hline 6 & $\begin{array}{l}\text { https://pubs.rsna.org/doi/10.1148/radiol.2020200269?url ver=Z39.88-2003\&rfr id=ori:ri } \\
\text { d:crossref.org\&rfr dat=cr pub\%3dpubmed }\end{array}$ \\
\hline 7 & $\frac{\text { https://www.jstage.jst.go.jp/article/bst/14/1/14 2020.01030/ pdf/-char/en }}{2}$ \\
\hline
\end{tabular}


medRxiv preprint doi: https://doi.org/10.1101/2020.05.22.20109777; this version posted August 19, 2020. The copyright holder for this preprint (which was not certified by peer review) is the author/funder, who has granted medRxiv a license to display the preprint in It is made available under a CC-BY-NC-ND 4.0 International license

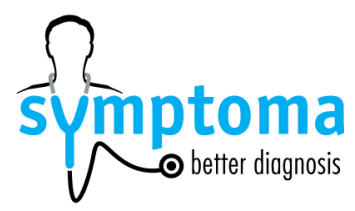

A benchmark of online COVID-19 symptom checkers

\begin{tabular}{|c|c|}
\hline 8 & https://www.ncbi.nlm.nih.gov/pmc/articles/PMC7029452/\#!po=32.1429 \\
\hline 9 & https://www.ncbi.nlm.nih.gov/pmc/articles/PMC7029452/\#!po=17.8571 \\
\hline 10 & https://www.ncbi.nlm.nih.gov/pmc/articles/PMC7036338/ \\
\hline 11 & https://www.thelancet.com/journals/lanres/article/PIIS2213-2600(20)30076-X/fulltext \\
\hline 12 & https://www.jjidonline.com/article/S1201-9712(20)30122-3/pdf \\
\hline 13 & https://www.ncbi.nlm.nih.gov/pubmed/32161941 \\
\hline 14 & https://onlinelibrary.wiley.com/doi/epdf/10.1111/ajt.15869 \\
\hline 15 & https://www.ncbi.nlm.nih.gov/pubmed/32100486 \\
\hline 16 & https://www.ncbi.nlm.nih.gov/pmc/articles/PMC7039714/ \\
\hline 17 & https://www.ncbi.nlm.nih.gov/pubmed/32188528 \\
\hline 18 & https://www.ncbi.nlm.nih.gov/pmc/articles/PMC7036342/ \\
\hline 19 & https://www.ncbi.nlm.nih.gov/pmc/articles/PMC7025910/ \\
\hline 20 & https://www.ncbi.nlm.nih.gov/pmc/articles/PMC7033720/ \\
\hline 21 & https://www.ncbi.nlm.nih.gov/pmc/articles/PMC7033720/\#!po=31.8182 \\
\hline 22 & $\begin{array}{l}\text { https://annals.org/aim/fullarticle/2763329/covid-19-risk-health-care-workers-case-repor } \\
\underline{t}\end{array}$ \\
\hline 23 & https://www.nature.com/articles/s41591-020-0819-2 \\
\hline 24 & https://link.springer.com/article/10.1007\%2Fs11604-020-00945-1 \\
\hline 25 & http://rimed.org/rimedicaljournal/2020/04/2020-04-50-case-tape.pdf \\
\hline 26 & https://www.karger.com/Article/FullText/507261 \\
\hline
\end{tabular}


medRxiv preprint doi: https://doi.org/10.1101/2020.05.22.20109777; this version posted August 19, 2020. The copyright holder for this preprint (which was not certified by peer review) is the author/funder, who has granted medRxiv a license to display the preprint in It is made available under a CC-BY-NC-ND 4.0 International license.

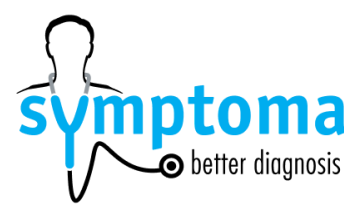

A benchmark of online COVID-19 symptom checkers

\begin{tabular}{|r|l|}
\hline 27 & $\underline{\text { https://jamanetwork.com/journals/jamacardiology/fullarticle/2763843 }}$ \\
\hline 28 & $\underline{\text { https://www.cdc.gov/mmwr/volumes/69/wr/mm6912e1.htm?s cid=mm6912e1 w }}$ \\
\hline 29 & $\underline{\text { https://www.kjronline.org/DOlx.php?id=10.3348/kjr.2020.0180 }}$ \\
\hline 30 & $\underline{\text { https://www.journalofinfection.com/article/S0163-4453(20)30148-1/fulltext }}$ \\
\hline 31 & $\underline{\text { https://www.thelancet.com/journals/lanhae/article/PIIS2352-3026(20)30074-0/fulltext }}$ \\
\hline 32 & $\underline{\text { https://www.ncbi.nlm.nih.gov/pubmed/32233816 }}$ \\
\hline 33 & $\underline{\text { https://www.thelancet.com/journals/lancet/article/PIIS0140-6736(20)30360-3/fulltext }}$ \\
\hline 34 & $\underline{\text { https://bestpractice.bmj.com/topics/en-gb/3000168/case-history }}$ \\
\hline 35 & $\underline{\text { is of covid19.pdf }}$ \\
\hline 36 & $\underline{\text { https://www.sciencedirect.com/science/article/pii/S0929664620301443?via\%3Dihub }}$ \\
\hline 37 & $\underline{\text { https://smw.ch/article/doi/smw.2020.20246 }}$ \\
\hline
\end{tabular}


medRxiv preprint doi: https://doi.org/10.1101/2020.05.22.20109777; this version posted August 19, 2020. The copyright holder for this preprint (which was not certified by peer review) is the author/funder, who has granted medRxiv a license to display the preprint in It is made available under a CC-BY-NC-ND 4.0 International license.

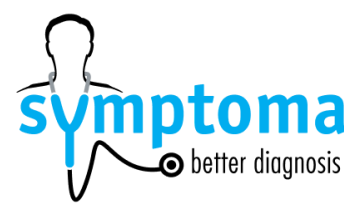

A benchmark of online COVID-19 symptom checkers

S4 Table. List of COVID-19 symptoms according to the WHO

Fever

Fatigue

Cough

Sneezing

Malaise

Rhinorrhea

Sore throat

Diarrhea

Headache

Dyspnea

S5 Table. Mapping between symptom checkers output texts and risk levels. All mappings were independently done by two different persons and conflicts resolved by

a third person's opinion.

\begin{tabular}{|c|c|c|}
\hline \multirow[t]{6}{*}{ Ada } & $\begin{array}{l}\text { Your symptoms are probably caused by other diseases that are more common than } \\
\text { COVID-19 }\end{array}$ & Low \\
\hline & It's unlikely that you're experiencing symptoms of COVID-19 & Low \\
\hline & $\begin{array}{l}\text { Based on what you've reported, you should take steps to monitor your health and practice } \\
\text { social distancing. You have none of the typical symptoms of COVID-19. However, in the } \\
\text { last } 14 \text { days, you've been in contact with a confirmed or probable COVID-19 case. Also, } \\
\text { you're in one of the groups at risk of developing a more serious form of the disease. }\end{array}$ & Medium \\
\hline & $\begin{array}{l}\text { The symptoms you have reported are present in some cases of COVID-19. You haven't } \\
\text { reported exposure to cases of COVID-19. However, you are in one of the groups at risk of } \\
\text { developing a more serious form of the disease. }\end{array}$ & Medium \\
\hline & $\begin{array}{l}\text { You have symptoms typical of COVID-19, and you're in one of the groups at risk of } \\
\text { having a more serious form of the disease. }\end{array}$ & Medium \\
\hline & It's possible that COVID-19 is causing your symptoms & Medium \\
\hline
\end{tabular}


medRxiv preprint doi: https://doi.org/10.1101/2020.05.22.20109777; this version posted August 19, 2020. The copyright holder for this preprint (which was not certified by peer review) is the author/funder, who has granted medRxiv a license to display the preprint in It is made available under a CC-BY-NC-ND 4.0 International license.

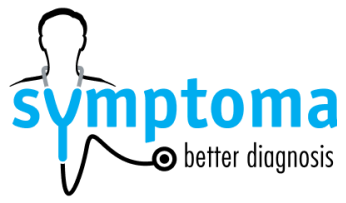

\section{A benchmark of online COVID-19 symptom checkers}

\begin{tabular}{|c|c|c|}
\hline & There is a high risk that COVID-19 is causing your symptoms & High \\
\hline \multirow[t]{3}{*}{ Apple } & You Should Practice Social Distancing & Low \\
\hline & You Should Self-Isolate & Medium \\
\hline & Contact Your Healthcare Provider & High \\
\hline \multirow[t]{2}{*}{ Babylon } & $\begin{array}{l}\text { It's unlikely that you are experiencing symptoms of coronavirus (COVID-19). But if you } \\
\text { develop a new or continuous cough, fever or difficulty breathing, start a new symptom } \\
\text { check. }\end{array}$ & Low \\
\hline & $\begin{array}{l}\text { The symptoms you mentioned sound worrying and could be caused by coronavirus } \\
\text { (COVID-19). Call } 999 \text { for an ambulance immediately and let them know you may have } \\
\text { symptoms of coronavirus. }\end{array}$ & Medium \\
\hline \multirow[t]{2}{*}{ CDC } & $\begin{array}{l}\text { Sorry you're feeling ill. Stay at home and monitor your symptoms. Call your provider if you } \\
\text { get worse (No COVID-19 risk) }\end{array}$ & Low \\
\hline & $\begin{array}{l}\text { Stay home and take care of yourself. Call your provider if you get worse. You have one or } \\
\text { more symptom that may be related to COVID- } 19\end{array}$ & Medium \\
\hline \multirow{3}{*}{$\begin{array}{l}\text { Cleveland } \\
\text { Clinic }\end{array}$} & You're at low risk for COVID-19. & Low \\
\hline & You're at medium risk for COVID-19. & Medium \\
\hline & You're at high risk for COVID-19. & High \\
\hline \multirow[t]{7}{*}{ Docyet } & $\begin{array}{l}\text { "Es besteht kein Grund zur Sorge! Basierend auf Ihren Angaben ist es ziemlich } \\
\text { unwahrscheinlich, dass Sie sich mit dem Coronavirus infiziert haben. Sie zeigen keine } \\
\text { Symptome von COVID-19. }\end{array}$ & Low \\
\hline & $\begin{array}{l}\text { Aktuell besteht kein wesentlicher Grund zur Sorge. Basierend auf Ihren Angaben ist es } \\
\text { ziemlich unwahrscheinlich, dass Sie sich mit dem Coronavirus infiziert haben. }\end{array}$ & Low \\
\hline & $\begin{array}{l}\text { Aktuell besteht kein wesentlicher Grund zur Sorge. Basierend auf Ihren Angaben ist es } \\
\text { relativ unwahrscheinlich, dass Sie sich mit dem Coronavirus infiziert haben. Sie } \\
\text { schildern jedoch einige typische Symptome eines Atemwegsinfekts (z.B. Grippe, } \\
\text { Bronchitis) oder einer Erkältung. }\end{array}$ & Low \\
\hline & $\begin{array}{l}\text { Sie sollten dringend ärztliche Hilfe aufsuchen. Sie haben typische Symptome einer } \\
\text { schweren Grippe oder Lungenentzündung geschildert. Auf Basis Ihrer Angaben ist es } \\
\text { jedoch nicht sehr wahrscheinlich, dass Sie sich mit dem Coronavirus infiziert haben. }\end{array}$ & Low \\
\hline & $\begin{array}{l}\text { Sie zeigen deutliche grippeähnliche Symptome und waren potentiell in Kontakt mit am } \\
\text { Coronavirus infizierten Personen. Es ist daher möglich, dass auch Sie sich angesteckt } \\
\text { haben. }\end{array}$ & Medium \\
\hline & $\begin{array}{l}\text { Sie zeigen erste grippeähnliche Symptome und waren potentiell in Kontakt mit am } \\
\text { Coronavirus infizierten Personen. Es ist daher möglich, dass auch Sie sich angesteckt } \\
\text { haben. }\end{array}$ & Medium \\
\hline & $\begin{array}{l}\text { "Bisher zeigen Sie keine auffälligen Symptome. Sie sind jedoch in Kontakt mit am } \\
\text { Coronavirus infizierten Personen gekommen. Es ist daher möglich, dass auch Sie sich } \\
\text { angesteckt haben, auf Grund der zweiwöchigen Ausbruchszeit jedoch noch keine } \\
\text { Symptome zeigen. }\end{array}$ & Medium \\
\hline
\end{tabular}


medRxiv preprint doi: https://doi.org/10.1101/2020.05.22.20109777; this version posted August 19, 2020. The copyright holder for this preprint (which was not certified by peer review) is the author/funder, who has granted medRxiv a license to display the preprint in It is made available under a CC-BY-NC-ND 4.0 International license.

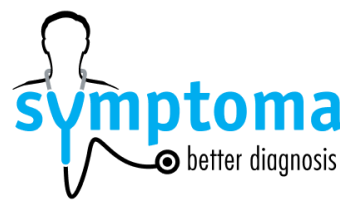

\begin{tabular}{|c|c|c|}
\hline & $\begin{array}{l}\text { Ihre Symptome deuten auf eine schwere Grippe bzw. Lungenentzündung hin. Außerdem } \\
\text { waren Sie potentiell in Kontakt mit am Coronavirus infizierten Personen. Es ist möglich, } \\
\text { dass auch Sie sich angesteckt haben. }\end{array}$ & Medium \\
\hline & $\begin{array}{l}\text { "Sie zeigen deutliche grippeähnliche Symptome sowie erste Anzeichen einer } \\
\text { Lungenentzündung. Außerdem waren Sie potentiell in Kontakt mit am Coronavirus } \\
\text { infizierten Personen. Es ist daher möglich, dass auch Sie sich angesteckt haben. }\end{array}$ & Medium \\
\hline \multirow[t]{3}{*}{ Providence } & $\begin{array}{l}\text { You do not report exposure to coronavirus (COVID-19) and do not have symptoms. You } \\
\text { don't report any symptoms of coronavirus infection, so your risk is low. You can use this } \\
\text { tool again or call your provider if anything changes, but in the meantime: }\end{array}$ & Low \\
\hline & $\begin{array}{l}\text { You might be infected with coronavirus (COVID-19). Please do one of the following: Call } \\
911 \text { for a life-threatening emergency. Schedule an evaluation with your primary care } \\
\text { physician. Speak with a provider at Express Care Virtual. }\end{array}$ & Medium \\
\hline & $\begin{array}{l}\text { Please do one of the following: Call } 911 \text { for a life-threatening emergency. Schedule an } \\
\text { evaluation with your primary care physician. Speak with a provider at Express Care Virtual. }\end{array}$ & High \\
\hline \multirow[t]{3}{*}{ Symptoma } & High risk for COVID-19 & High \\
\hline & Medium risk for COVID-19 & Medium \\
\hline & Low risk for COVID-19 & Low \\
\hline \multirow[t]{2}{*}{ Infermedica } & $\begin{array}{l}\text { Your symptoms do not suggest that you have COVID-19. Continue following the common } \\
\text { measures and government directives to avoid contracting COVID-19. Remember that your } \\
\text { symptoms may also result from other diseases and may require medical consultation - } \\
\text { this interview targets the COVID-19 infection. If your symptoms seem severe and you are } \\
\text { worried, contact your doctor or local health authorities. }\end{array}$ & Low \\
\hline & $\begin{array}{l}\text { Your symptoms are worrisome and may be related to COVID-19. Call your local } \\
\text { COVID-19-related healthcare number. Depending on the country, this may be a telephone } \\
\text { line issued by the Ministry of Health or Health Department. }\end{array}$ & Medium \\
\hline \multirow[t]{5}{*}{ Your.MD } & $\begin{array}{l}\text { There's nothing at present to suggest that you have coronavirus (COVID-19). Please } \\
\text { practice physical/social distancing. }\end{array}$ & Low \\
\hline & You may have coronavirus (COVID-19). & Medium \\
\hline & You may still be at risk of coronavirus (COVID-19). & Medium \\
\hline & You're highly likely to have coronavirus (COVID-19). & High \\
\hline & $\begin{array}{l}\text { Call an ambulance immediately. Please tell them you have symptoms that may be caused } \\
\text { by coronavirus (COVID-19). }\end{array}$ & High \\
\hline
\end{tabular}


medRxiv preprint doi: https://doi.org/10.1101/2020.05.22.20109777; this version posted August 19, 2020. The copyright holder for this preprint (which was not certified by peer review) is the author/funder, who has granted medRxiv a license to display the preprint in It is made available under a CC-BY-NC-ND 4.0 International license.

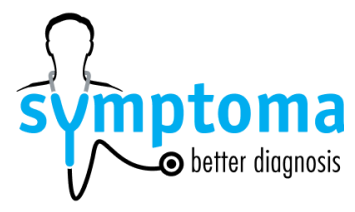

A benchmark of online COVID-19 symptom checkers

S6 Table. Full table of sensitivity, specificity, accuracy, F1 score and MCC for all symptom checkers (COVID-19 positive defined by "high risk" for non binary symptom checkers)

\begin{tabular}{llllll|} 
Symptom checker & sensitivity & specificity & accuracy & F1 Score & MCC \\
Ada & 0,14 & 1.00 & 0.57 & 0.24 & 0.27 \\
Apple & 0.22 & 0.69 & 0.46 & 0.29 & -0.10 \\
Babylon & 0.90 & 0.33 & 0.62 & 0.70 & 0.29 \\
CDC & 0.94 & 0.29 & 0.61 & 0.71 & 0.30 \\
Cleveland Clinic & 0.32 & 0.74 & 0.53 & 0.40 & 0.07 \\
Docyet & 0.16 & 1.00 & 0.58 & 0.27 & 0.29 \\
Infermedica & 0.78 & 0.83 & 0.80 & 0.80 & 0.61 \\
Providence & 0.32 & 0.72 & 0.52 & 0.40 & 0.05 \\
SF-COS & 0.90 & 0.66 & 0.78 & 0.80 & 0.58 \\
SF-DIST & 0.52 & 0.70 & 0.61 & 0.57 & 0.22 \\
Symptoma & 0.88 & 0.97 & 0.93 & 0.92 & 0.85 \\
Your.MD & 0.14 & 1.00 & 0.57 & 0.24 & 0.27 \\
\hline
\end{tabular}


medRxiv preprint doi: https://doi.org/10.1101/2020.05.22.20109777; this version posted August 19, 2020. The copyright holder for this preprint (which was not certified by peer review) is the author/funder, who has granted medRxiv a license to display the preprint in It is made available under a CC-BY-NC-ND 4.0 International license .

\section{Symptoma}

\section{A benchmark of online COVID-19 symptom checkers}

S7 Table. Full table of sensitivity, specificity, accuracy, F1 score and MCC for all symptom checkers (COVID-19 positive defined by "medium risk or "high risk" for non binary symptom checkers)

\begin{tabular}{llllll} 
Symptom checker & sensitivity & specificity & accuracy & F1 Score & MCC \\
Ada & 0,36 & 0.67 & 0.51 & 0.42 & 0.03 \\
Apple & 0.98 & 0.17 & 0.57 & 0.70 & 0.25 \\
Babylon & 0.90 & 0.33 & 0.62 & 0.70 & 0.29 \\
CDC & 0.94 & 0.29 & 0.61 & 0.71 & 0.30 \\
Cleveland Clinic & 0.98 & 0.41 & 0.69 & 0.76 & 0.47 \\
\hline Docyet & 0.16 & 1.00 & 0.58 & 0.27 & 0.29 \\
\hline Infermedica & 0.78 & 0.83 & 0.80 & 0.80 & 0.61 \\
Providence & 0.98 & 0.38 & 0.68 & 0.75 & 0.45 \\
SF-COS & 0.90 & 0.66 & 0.78 & 0.80 & 0.58 \\
SF-DIST & 0.52 & 0.70 & 0.61 & 0.57 & 0.22 \\
Symptoma & 0.94 & 0.88 & 0.91 & 0.91 & 0.83 \\
Your.MD & 0.94 & 0.32 & 0.63 & 0.72 & 0.33 \\
\hline
\end{tabular}


medRxiv preprint doi: https://doi.org/10.1101/2020.05.22.20109777; this version posted August 19, 2020. The copyright holder for this preprint (which was not certified by peer review) is the author/funder, who has granted medRxiv a license to display the preprint in It is made available under a CC-BY-NC-ND 4.0 International license

SU better diagnosis

\section{A benchmark of online COVID-19 symptom checkers}
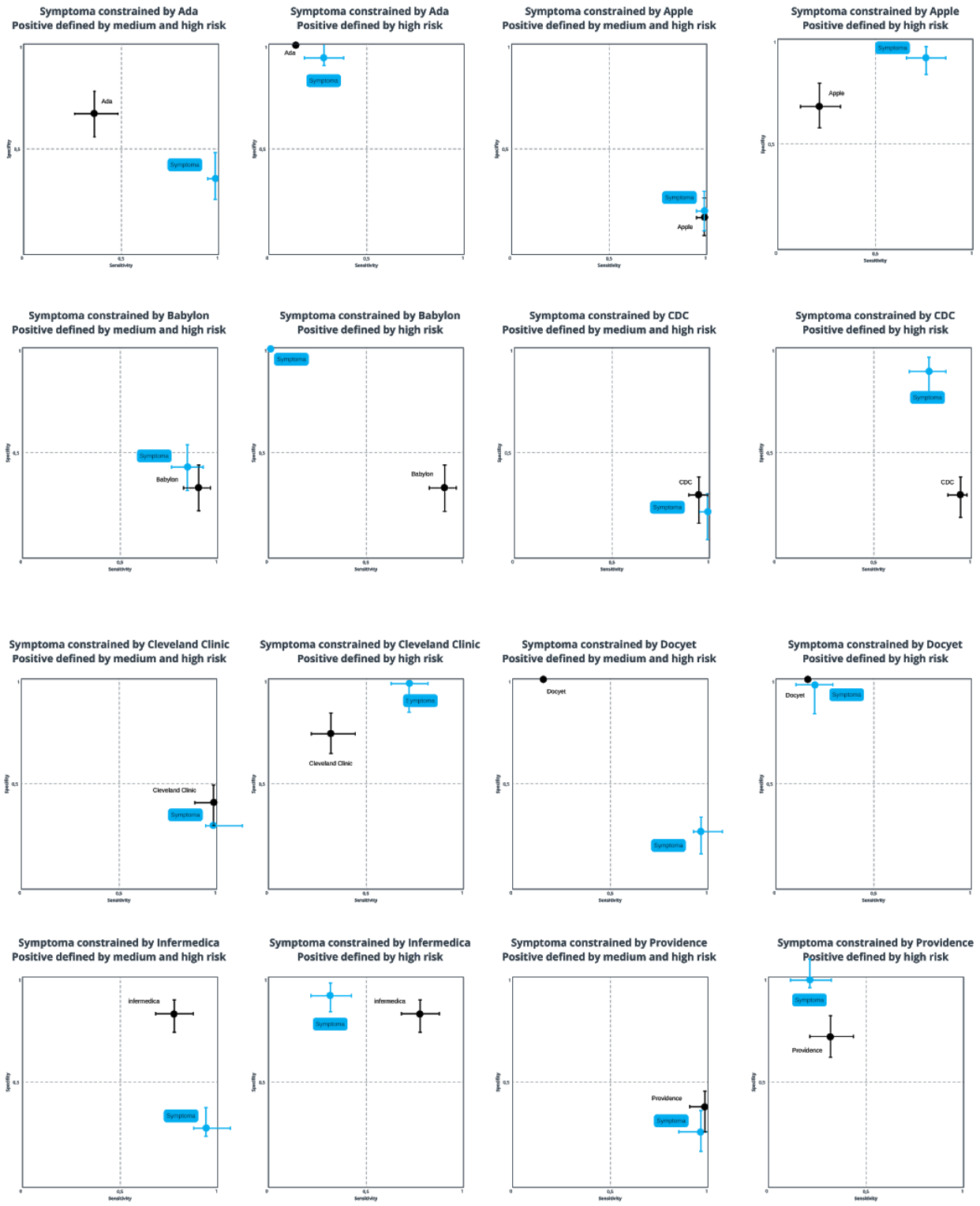

Symptoma constrained by Symptoma
Positive defined by medium and high risk
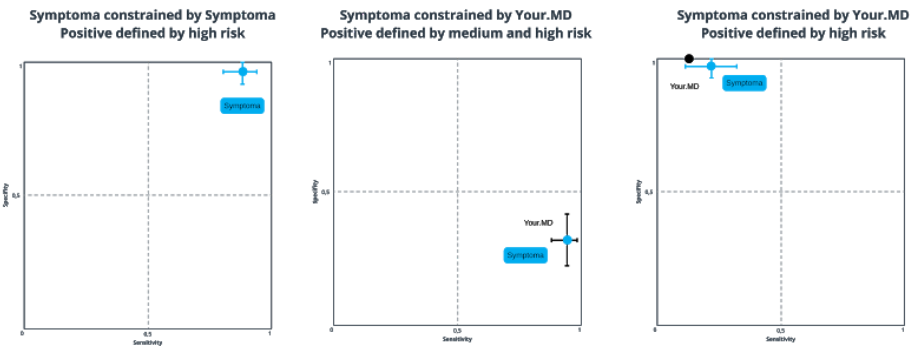

S8 Fig. Sensitivity vs specificity for all symptom checkers and Symptoma input constraint respectively by each symptom checker 
medRxiv preprint doi: https://doi.org/10.1101/2020.05.22.20109777; this version posted August 19, 2020. The copyright holder for this preprint (which was not certified by peer review) is the author/funder, who has granted medRxiv a license to display the preprint in It is made available under a CC-BY-NC-ND 4.0 International license.

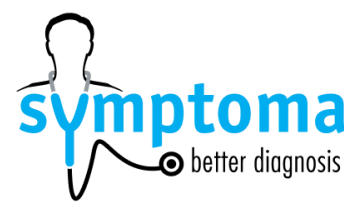

A benchmark of online COVID-19 symptom checkers

S9 Table. Full table of sensitivity, specificity, accuracy, F1 score and MCC for Symptoma constrained by each symptom checker (COVID-19 positive defined by "high risk" for non binary symptom checkers)

\begin{tabular}{|llllll} 
Symptoma costrained by & sensitivity & specificity & accuracy & F1 Score & MCC \\
Ada & 0.28 & 0.94 & 0.61 & 0.42 & 0.30 \\
Apple & 0.76 & 0.92 & 0.84 & 0.82 & 0.69 \\
Babylon & 0.00 & 1.00 & 0.50 & 0.00 & n/a \\
CDC & 0.78 & 0.89 & 0.83 & 0.82 & 0.68 \\
Cleveland Clinic & 0.72 & 0.99 & 0.85 & 0.83 & 0.73 \\
Docyet & 0.20 & 0.98 & 0.59 & 0.33 & 0.29 \\
Infermedica & 0.32 & 0.92 & 0.62 & 0.45 & 0.30 \\
Providence & 0.22 & 0.99 & 0.60 & 0.35 & 0.32 \\
Your.MD & 0.22 & 0.98 & 0.60 & 0.35 & 0.31 \\
\hline
\end{tabular}

S10 Table. Full table of sensitivity, specificity, accuracy, F1 score and MCC for Symptoma constrained by each symptom checker (COVID-19 positive defined by "medium risk" or "high risk" for non binary symptom checkers)

\begin{tabular}{llllll}
\hline Symptoma costrained by & sensitivity & specificity & accuracy & F1 Score & MCC \\
Ada & 0.98 & 0.36 & 0.67 & 0.75 & 0.44 \\
Apple & 0.98 & 0.20 & 0.59 & 0.70 & 0.28 \\
Babylon & 0.84 & 0.43 & 0.63 & 0.70 & 0.30 \\
CDC & 0.98 & 0.21 & 0.59 & 0.71 & 0.29 \\
Cleveland Clinic & 0.98 & 0.30 & 0.64 & 0.73 & 0.38 \\
Docyet & 0.96 & 0.27 & 0.62 & 0.71 & 0.32 \\
Infermedica & 0.94 & 0.28 & 0.61 & 0.71 & 0.29 \\
Providence & 0.96 & 0.26 & 0.61 & 0.71 & 0.31 \\
Your.MD & 0.94 & 0.32 & 0.63 & 0.72 & 0.33 \\
\hline
\end{tabular}


medRxiv preprint doi: https://doi.org/10.1101/2020.05.22.20109777; this version posted August 19, 2020. The copyright holder for this preprint (which was not certified by peer review) is the author/funder, who has granted medRxiv a license to display the preprint in It is made available under a CC-BY-NC-ND 4.0 International license.

Obetter diagnosis

\section{A benchmark of online COVID-19 symptom checkers}

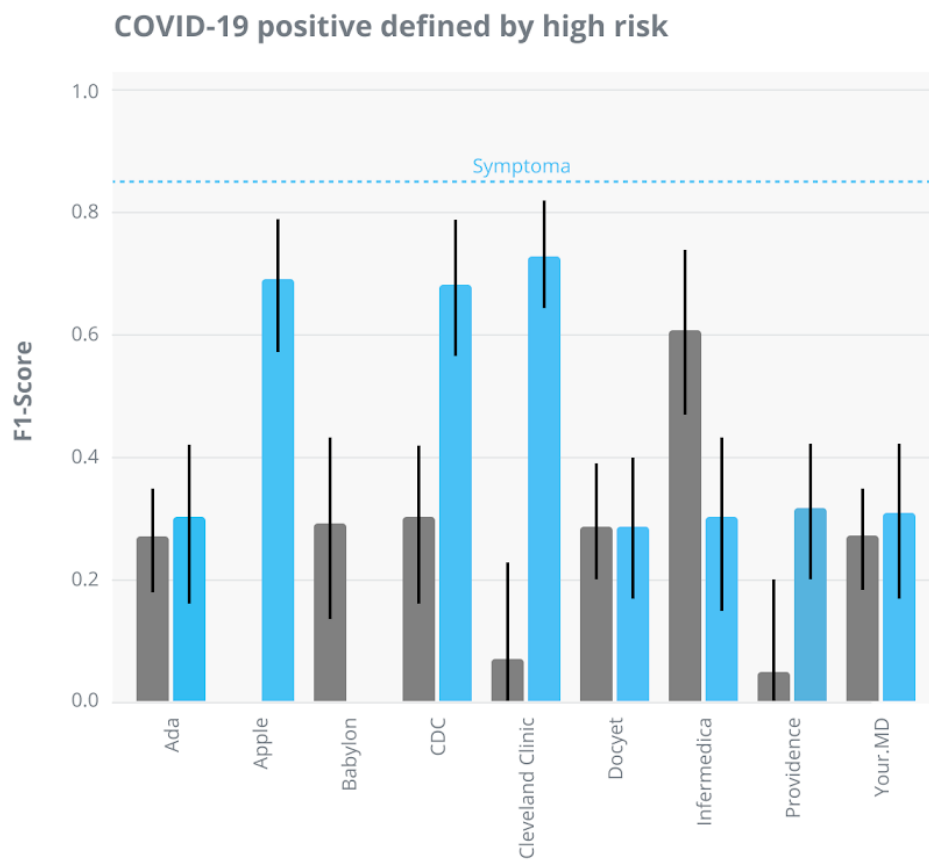

- Symptoma (input constrained)

COVID-19 symptom checker

COVID-19 positive defined by medium and high

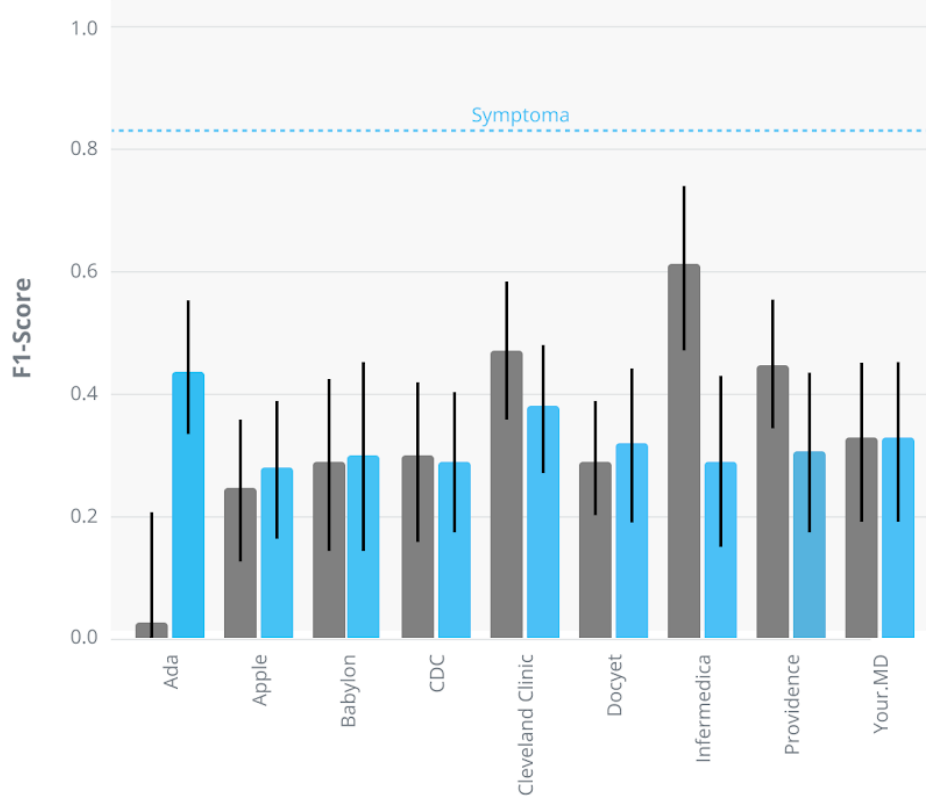

S11 Fig. Pairwise comparison between all symptom checkers and Symptoma based on the MCC if only the subset of symptoms used by one checker is also used for Symptoma. 